Summary Report of NIST's Industry-Government Consortium Research Program on Flowmeter Installation Effects With Emphasis on the Research Period January - September 1991: The Reducer
G. E. Mattingly

T. T. Yeh

U.S. DEPARTMENT OF COMMERCE

Technology Administration

National Institute of Standards

and Technology

Chemical Science and Technology Laboratory

Process Measurements Division

Fluid flow Group

Gaithersburg. MD 20899
U.S. DEPARTMENT OF COMMERCE Rockwell A. Schnabel, Acting Socretary MATONAL INSTITUTE OF STANDARDS AND TECHNOLOOY

John W. Lyons, Director 



\section{Summary Report of NIST's}

Industry-Government

Consortium Research

Program on Flowmeter

Installation Effects

With Emphasis on the

Research Period

January - September 1991:

The Reducer

\section{G. E. Mattingly \\ T. T. Yeh}

U.S. DEPARTMENT OF COMMERCE

Technology Administration

National Institute of Standards

and Technology

Chemical Science and Technology Laboratory

Process Measurements Division

Fluid Fow Group

Gaithersburg. MD 20899

December 1991

Issued February 1992

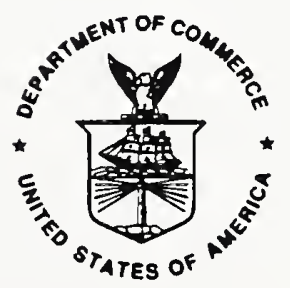

U.S. DEPARTMENT OF COMMERCE Rockwell A. Schnabel, Acting Socretary MATIONAL INSTITUTE OF STANDARDS AND TECHNOLOGY

John W. Lyons, Director 



\section{PREFACE}

The research results reported in this document were produced with the support of a National Institute of Standards and Technology (NIST) initiated industry-government consortium. This is an established cooperative research effort on generic technical issues to produce industry needed flow metering improvements. In this mode of operation, there is a high degree of interaction between the representatives of the consortium member companies and the NIST researchers. These interactions include: (1) the planning of the specific focus of the NIST research efforts, (2) the discussions and analyses of the results obtained, and (3) the conclusions drawn for the particular phase of the work. For this reason, it is pertinent to acknowledge both the support given to this phase of the research program and the technical contributions made by the representatives of the consortium members.

The current consortium as of October 1991 is, alphabetically:
1. Ametek-McCrometer
2. Chevron Oil
3. Controlotron
4. Daniel Industries
5. Dow Chemical Co.
6. E.I. Dupont de Nemours
7. Ford Motor Co.
8. Gas Research Institute*
9. Gas Unie (The Netherlands)
10. Instrument Testing Service
11. Kimmon Mfg. Ltd. (Japan)
12. NOVA Husky (Canada)
13. Pacific Gas \& Electric Co.
14. Rosemount

*Specific acknowledgment is due to Dr. Kiran M. Kothari and Mr. John R. Gregor of the Gas Research Institute (GRI). Both their support of this program and their technical input in the discussions and analyses of results and in the conclusions drawn are gratefully acknowledged. 



\section{TABLE OF CONTENTS}

Page

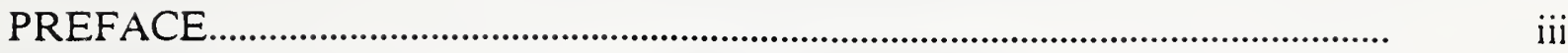

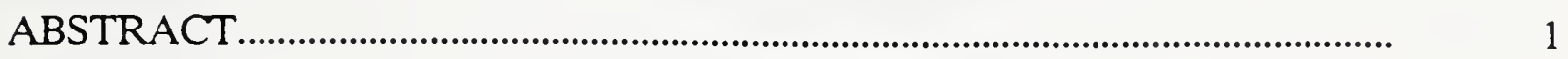

INTRODUCTION ..................................................................................................

PREVIOUS RESULTS.........................................................................................

PIPEFLOW MEASUREMENTS RESULTS

1. Downstream of A Reducer.

2. Downstream of $A$ Tee Used As An Elbow.

3. Downstream of A Tee Used As An Elbow and $A$ 7-Tube Tube Bundle.......................................................................

4. Downstream of An Elbow and a 19-Tube Tube Bundle

5. Downstream of An Elbow and a 19-Tube Tube Bundle Installed in Two Locations.

2. Orifice and Turbine Meter Downstream of An Elbow and a 19-Tube Tube Bundle.

3. Orifice Meter Downstream of an Elbow with Closely Installed 19-Tube Tube Bundle with 5D Pipe Downstream.

METER PERFORMANCE VARIATIONS VERSUS INSTALLATION POSITION FROM SELECTED NON-IDEAL PIPING AND TUBE BUNDLE ARRANGEMENTS

1. Orifice Meter.

2. Turbine Meter.

CONCLUSIONS.

ACKNOWLEDGMENTS.

REFERENCES 


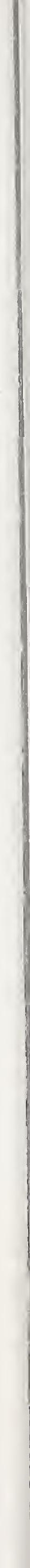




\title{
Summary Report of NIST's Industry-Government Consortium Research Program on Flowmeter Installation Effects with Emphasis on the Research Period January - September 1991: The Reducer
}

\author{
G.E. Mattingly \\ T.T. Yeh \\ Fluid Flow Group \\ Process Measurements Division \\ Chemical Science and Technology Laboratory \\ National Institute of Standards and Technology \\ Gaithersburg, Maryland 20899
}

\section{ABSTRACT}

This report presents recent results obtained in a consortium-sponsored research program on flowmeter installation effects being conducted at NIST-Gaithersburg, MD. This project is a collaborative one that has been underway for some eight years; it is supported by an industrygovernment consortium that meets twice yearly to review and discuss recently obtained results and to plan subsequent phases of the work. This report contains the results and conclusions of the meeting of this consortium at NIST-Gaithersburg, MD. in October 1991.

The objective of this research program is to produce improved flowmeter performance when meters are installed in non-ideal conditions. Ideal meter installation conditions are those where long straight lengths of constant diameter piping precede the meter locations. Actual installations seldom conform to these conditions. The objective of this program is being attained via our research strategy to:

(a) measure, understand, and quantify the salient features of non-ideal pipe flows from such pipeline elements as elbows, reducers, valves, etc. or combinations of these,

(b) correlate meter-factor shifts for selected types of flowmeters installed downstream from these pipeline elements with quantified flow features so as to be able to predict meter performance accurately in non-ideal installations, and,

(c) disseminate the resulting technology through appropriate channels such as publishing our results in pertinent journals and upgrading fluid metering standards so that improved flow meter performance is obtained in actual nonideal conditions.

This research effort has also included experimental studies of the flow into and out of several tube bundle flow conditioners. These results have produced, for the first time, detailed descriptions of the effects these devices have on swirling pipe flows. The performances of both orifice and turbine meters have also been determined for different installation locations downstream of arrangements of selected pipeline elements - such as single and double elbows - both without and with tube bundles.

Specifically, this report contains measurements of the pipeflows produced downstream of the conventional reducer. Results are given for the performance characteristics of a range of orifice meter geometries and a specific turbine meter in these pipe flows. Also included are the velocity profile measurements downstream of the tee used as an elbow and several arrangements of tube bundles installed downstream of the single elbow and the tee used as an elbow. 


\section{INTRODUCTION}

The increasing scarcity of fluid resources and the rising value of fluid products are placing new emphases on improved flow measurements. Improvements are sought from many starting points. For example, meters are being retrofitted into fluid systems that were not designed for them. This invariably means the flowmeters are being inserted into "non-ideal" installation conditions. By "non-ideal" is meant any of the infinitude of conditions where the upstream piping conditions produce pipeflow distributions that differ from that associated with fully developed flow that occurs in ideal installation conditions. By "ideal" is meant installation conditions where the meter location is preceded by sufficiently long, straight lengths of constant diameter piping that the meter's performance is not changed when the meter is installed at any position further downstream. Pipeflows can also be termed "ideal" when the time averaged and turbulent velocity profiles conform to those for fully developed, equilibrated pipe flows established for the pertinent fluid and flow conditions.

The prevalent concern in today's flow measurement community is for increased metering accuracy levels. These are desired for existing meter systems - either by upgrading the flow conditions that enter the installed meter or by replacing the device itself or its auxiliary components so that accuracy levels are increased.

Flow conditioning devices of one geometry or another are frequently recommended in metering standards for improving flowmeter performance when installation conditions are not ideal. However, the pipeflows generated by these devices have to be considered with respect to the flowmeter installed downstream of the specific piping configuration, the pipeflows centering it, the pertinent parameters that control pipeflow phenomena, and the factors that influence the performance of the particular meter. It will be shown in what follows that certain flow conditioner installations can produce serious deviations from the performance of specific meters in ideal installation condítions.

When flow conditioners cannot be used to remedy a "non-ideal" installation condition, it has been conventional practice to calibrate the actual piping and meter configuration as a complete unit. When this is not possible or unreasonable, an alternative procedure may be used which has been put forth for the first time in this research program as described below.

The industry-government consortium research program on flowmeter installation effects that is currently underway at NIST is designed to help improve fluid metering performance when installation conditions are not ideal. The design of the program is to produce a basic understanding of the flow phenomena that are produced in prevalently encountered, non-ideal pipe flows and to quantify these phenomena relative to reference fluid dynamic conditions. When these phenomena and their quantified characteristics are correlated with the performance of specific types of meters, it is considered feasible to predict and achieve satisfactory measurements in non-ideal meter installations. The success of this approach has been demonstrated using several different types of flowmeters installed downstream of several different pipe elbow configurations, $[1-5]^{1}$. This approach is being incorporated into the new standards on methods for establishing flowmeter installation effects, [6].

The experimental flow metering research program underway at NIST is based upon the measurements of pipe flows from selected piping configurations using laser Doppler velocimetry (LDV). The program is intended to use the basic experimental research tools available to the fluid dynamicist to measure, understand, and parameterize the salient features

1 Square bracketed integers refer to references given below. 
of the pipeflow phenomena produced by pipeline configurations. The successive phase of the program is to evaluate quantitatively how these phenomena influence fluid meters and how to handle these effects. Selections of piping configurations and pipeline elements such as flow conditioners are done by vote of the consortium membership; one or two such configurations can be done in one year.

The LDV techniques that have been and are being applied to measure the basic pipe flows can also be used to measure the effects of other pipeline elements - valves, flow conditioning elements (for fluid velocity or pulsations, etc.), muxing devices, generic flowmeter geometries or combinations of these. The resulting understanding should provide the basis for establishing basic reference conditions and assessing perturbations to these to improve the effectiveness of these devices and, in turn, the performances of flowmeters installed downstream of such piping configurations. It is expected that improved flowmeter performance will be significant and wide spread over a broad range of conditions. Assuredly, it will enhance the custody transfer of valuable fluid resources and the optimization of industrial processes involving costly fluid products through better control produced by better fluid flow measurements.

In the present study, the fluid is water and the piping is $52.5 \mathrm{~mm}$ (2 inch diameter), smooth, stainless steel. Water temperature is controlled using a heat exchanger to maintain a set temperature of $20^{\circ} \mathrm{C}$. The relative roughness of this pipe has been measured with a profilometer to indicate a value of $0.006 \%$ based on interior pipe diameter. Diametral Reynolds numbers range from $10^{4}$ to $10^{5}$ using bulk average velocity. According to the concepts of dynamic similitude, the results of the present research program should predict a range of other flows - both liquids and gases - in geometrically scaled piping configurations when pertinent parameters match those in our experiments. The pertinent parameters considered important in the current experiments are Reynolds numbers and pipe relative roughness; it is assumed the fluid compressibility and gravitational effects are negligible. All pertinent reference conditions regarding pipeflows are completely documented according to basic fluid flow principles. When all these conditions occur in other, geometrically scaled pipe systems, in liquids or gases, the flows should be appropriately scaled versions of our results.

It is expected that the resuits from this program will enable satisfactory flow measurements to be made in many situations where installation conditions are not ideal. For situations where it is not possible or desirable to install flow conditioning elements to remedy pipeflow anomalies, it is suggested here that, where specific calibration of the whole meter installation cannot be done, the proposed meter performance prediction technique be used.

When the performance of flowmeters - similar to or different from those selected -is determined by calibration tests in conditions that match exactly or are scaled correctly to those in these experiments, meter performance can be correlated to pipe flow parameters. Such correlations, when done for the pertinent range of "non-ideal" installations and for the appropriate flow meters, should produce the desired specifications for installing these meters. When this is achieved by flowmeter manufacturers or users alike, it should then be possible to predict and achieve satisfactory metering performance for these meters in similar non-ideal installations.

\section{PREVIOUS RESULTS}

Previous phases of this research program have produced LDV measurements of the pipeflows in the downstream piping from single and double elbow configurations. Conventional, longradius elbows are used in all of these studies; the radius of the centerline through these elbows is 1.5 pipe diameters. The previous and currently studied piping configurations are sketched 
in figure 1 with the coordinate system selected. Detailed results of these studies are given in [1-5]; summary descriptions are given in [7-9].

Previous phases of this research program have also produced data for the performance of orifice and turbine meters installed downstream of selected single and double elbow piping configurations, see [8-9]. Additionally, the demonstration of the success of the abovedescribed prediction scheme for attaining accurate flowmeter performance for these types of meters installed downstream of these elbow configurations is demonstrated in [3-5]. The effects on orifice and turbine meters produced by an upstream piping tee which is used as an elbow are given in [1]. The effects on these types of meters produced by a concentric reducer are also given in [1].

Earlier phases of this research program determined the effects on orifice and turbine meters of several types of tube bundles installed downstream of the elbow configurations and the tee used as an elbow. The tube bundles used were the prevalently used 19 tube concentric design and the 7 tube arrangement. Figure 2 shows these tube bundles with dimensions given in millimeters. These units are either identical to the practically used units ( 7 tube) for $50 \mathrm{~mm}$ diameters, or geometrically scaled versions of the prevalent unit used in large pipe sizes according to orifice meter technology (19 tube).

In all of the results that follow, non-dimensionalized quantities will be used. Lengths and velocities are normalized using the pipe diameter, $D$ and bulk-average velocity, respectively. Meter performances are given via orifice discharge coefficients and Strouhal numbers, respectively, for the selected orifice and turbine meters.

The results obtained for the conditions tested to date show that while the 19-tube tube bundle successfully removes swirl from these pipeflows it apparently produces other effects in the streamwise velocity profiles that cause several different perturbations on orifice meter performance. The effects on the specific design of turbine meter selected for these tests were less varied than those for orifice meters, see [4 and 9].

The tube bundle designs tested in recent phases of this program are installed downstream of the piping configurations as shown in figure 3. The coordinate $Z$ has its origin in the exit plane of the elbow as shown in figure 1 and 3. The 19-tube tube bundle shown in figure 2(a) is essentially $2 \mathrm{D}$ in length; meter position downstream from the exit plane of this conditioner is denoted by length $\mathrm{C}$ in diameters, see figure 3 . The 7-tube tube bundle, installed as shown in figure $3(\mathrm{~b})$ has its entrance plane at the same $\mathbf{Z}$ location as that used for the 19 tube; the meter position downstream from each tube bundle is denoted by $C$. This 7 -tube tube bundle is $3 \mathrm{D}$ in length.

\section{PIPEFLOW MEASUREMENT RESULTS}

1. Downstream of a Reducer. The $75 \mathrm{~mm}$ (3in) to $50 \mathrm{~mm}$ (2in) diameter pipe reducer installation shown in figure 1 was arranged so that over one hundred (100) pipe diameters of straight, constant diameter piping preceded the reducer. Upstream of this length of piping the inlet flow was arranged to have a special, radial inlet so that no axial vorticity was produced by this entrance condition. This long inlet pipe to the reducer had a single flange joint which was specially aligned and fitted with pins to assure a concentric constant diameter joint which could be repeatably reassembled. Although the pipeflow produced by this inlet pipe has not as yet been directly measured, all previous LDV measurements downstream from the single elbow showed that the effects of the elbow were negligible after about 30 pipe diameters for Reynolds number 100,000 and relative roughness $0.006 \%$. Since in this $75 \mathrm{~mm}$ 
(3in) diameter pipe, the Reynolds number was 66,000 (corresponding to 100,000 in the $52 \mathrm{~mm}$ pipe), the pipeflow profile after 100 diameters of this piping and the same pipe roughness conditions was assumed to be fully developed. Figure 4 presents LDV measurements of the mean axial velocity component versus horizontal radial position for Reynolds number 100,000. The dashed curve is the fully developed, equilibrated pipeflow distribution put forth by Bogue and Metzner, [10]. Figure 5 presents results for axial velocity profiles versus vertical radial position. In both figures 4 and 5, the effects of the reducer produce, near the exit of the reducer, very uniform velocity profiles as compared to the fully developed distribution for these conditions. At about 20D downstream from the exit of this reducer the mean velocity profiles closely approximate the fully developed pipeflow distribution for these conditions. However, beyond the 20D location these profiles show that the center core of this pipeflow produces velocities in excess of the fully developed distribution in the center portion of the pipeflow. This fast core of flow extends to about one-half of a pipe radius on either side of the pipe centerline; the peak level measured in these results is about $5 \%$ in excess of the centerline value for the fully developed distribution. Figures 4 and 5 indicate that these pipeflows are essentially axisymmetric at all stations measured.

Figure 6 presents vertical mean velocity profiles versus horizontal radial position; at different downstream positions for $\operatorname{Re}=100,000$. These results show that the reducer does not appear to produce swirl for these conditions.

Figures 7 and 8 present, respectively, the root-mean-square (r.m.s.) components of the axial and vertical components of the turbulent velocity versus horizontal radial position from the pipe centerline. These measurement results for different downstream distances are plotted with the results measured by Laufer as shown via the dashed profile, see [11]. These results indicate that the turbulent intensity near the exit of the reducer in the center of the pipe is lower than the result produced by Laufer. Near the pipe walls, the intensity exceeds the levels measured by Laufer. The lower turbulent intensity in the center of the pipe is due to the fact that the turbulence is convected through the reducer without significant change and is normalized with the higher bulk average velocity in the $52 \mathrm{~mm}$ pipe.

2. Downstream from a Tee Used As An Elbow. The tee used as an elbow configuration shown in figure 1 was arranged so that the upstream piping was about seventy (70) diameters of straight constant diameter piping. Upstream of this length of pipe were positioned two (2) flow conditioners. When LDV measurements were made of the profiles exiting this 70 diameter pipe length, they were found to be fully developed, equilibrated pipeflows. With these reference profiles entering the tee, the exiting pipeflows can be interpreted, for this conventional piping configuration, to be due to this single piping element.

Figures 9 and 10, respectively, present measurement results for the time-averaged axial component of the velocity versus horizontal and vertical radial position from the pipe centerline for different downstream positions from the tee for $\operatorname{Re}=100,000$. The fully developed distribution given by Bogue and Metzner is shown via the dashed profile. Figure 9 shows that the streamwise velocity component is symmetrical about the plane of symmetry through the tee. The traverse in the plane of the tee shows high speed flow toward the outside of the turn produced by this tee. Near the inside portion of the turn, figure 10 shows that a region of slow flow is present near the inside of turn produced by the tee. However, both figures 9 and 10 indicate that after about 6 diameters from the exit of the tee both the horizontal and vertical profiles of the axial velocity component attain essentially axisymmetric distributions. However, figures 9 and 10 also indicate that, for these conditions, these axisymmetric and quite uniform velocity profiles do not conform well to the fully developed distribution even twenty diameters from the tee. 
Figure 11 presents LDV results for the time-averaged vertical component of the velocity along the diameter perpendicular to the plane of the tee. The profile near the tee indicates that a dual eddy swirl distribution is generated by the turning action of this tee. Looking upstream the secondary axial vorticity on the left portion of the pipeflow is rotating clockwise; on the right, the rotation is counterclockwise. However, by the downstream location six diameters from the tee exit these vortices seem to be completed dissipated. This dissipation is more rapid than that observed for the single elbow, [4].

Figures 12 and 13 present measurements of the r.m.s. streamwise and vertical components of the turbulence, respectively, along the diameter perpendicular to and in the plane of symmetry of the tee. In each case, the levels of turbulence that exit the tee are higher than those leaving the single elbow for the same Reynolds number and pipe roughness conditions. These enhanced turbulence levels are interpreted to be due to the abrupt turning action of the tee used as an elbow. Furthermore, there is the cavity associated with the tee used as an elbow that can provide regions where shear layer instabilities can create turbulent conditions and therefore dissipative mechanisms not present in the flow through the conventional, long radius elbow.

For improved flow metering, the tee used as an elbow is concluded to have several advantages over the conventional elbow. First, having ready access to the downstream piping through the blind flange enables convenient meter inspection, insertion, or removal of flow conditioning elements. Secondly, the geometry of the tee used as an elbow creates secondary flow patterns but these are dissipated rapidly in the downstream piping. However, the distorted, timeaveraged, streamwise component of the velocity does not agree well with the fully developed distribution for these conditions eve after twenty diameters from the exit of the tee. Although not measured, the pressure loss through the tee is probably higher than that in the long radius elbow.

3. Downstream of A Tee Used As An Elbow and A 7-Tube Tube Bundle. Figures 14 and 15 present profiles of the time-averaged, streamwise velocity components along diameters perpendicular to and in the plane of the tee, respectively. The tube bundle shown in figure 2(b) is installed as shown in figure 3(a). The results presented in figures 14 and 15 show that just downstream from the tube bundle, at $Z=8.22$ which is within $2 \mathrm{D}$ from the exit of the tube bundle, the distributions show the jetting effects of the flows from the individual tubes. Also shown is the relatively rapid transformation of these profiles to closely resemble fully developed distributions. Within a distance of $5 \mathrm{D}$ to $10 \mathrm{D}$ downstream of the exit plane of the tube bundle at $Z=11.72$ and 16.72 , the profiles show differences less that $5 \%$ from the fully developed distributions.

These distributions which so closely approximate the fully developed profiles in these regions downstream of this 7 tube tube bundle are interpreted to be the reasons for the performance of orifice meters installed in these locations downstream of this tube bundle, [1]. By contrast, the corresponding pipeflow distributions measured downstream of the more conventional 19 . tube tube bundle develop differently. The profiles just downstream of the 19 tube tube bundle produced very uniform velocity distributions in which the major portion of the center core of the pipeflow was quite slow in comparison with the fully developed distributions. This condition produced negatively shifted orifice discharge coefficients. Further downstream, the profiles were found to produce, in the center of the pipeflow, an "over-shoot" condition where the velocity exceeded that for the fully developed distribution. These distributions produced positively shifted orifice coefficients. These are interpreted to be due to the combined effects of high velocity flow at and near the pipe centerline and correspondingly reduced streamwise velocity components near the pipe wall which produce reduced pressure levels at the upstream tap locations, see $[1,2]$. It is noted that the positively shifted orifice discharge coefficient 
condition prevails for extended lengths downstream of the 19-tube tube bundle. For test conditions of $\mathrm{Re}=10^{5}$ and large beta ratios, orifice meters required some 50 diameters of downstream distance before discharge coefficients attained values equal to those pertinent to the fully developed pipeflow condition and maintained these values for installation positions further downstream.

Figure 16 presents measurement results for the vertical component of the time-averaged velocity along the diameter perpendicular to the plane of the tee. These show that these velocities are below the $4 \%$ level at $Z=8.22$ and subside to even lower magnitudes beyond this position.

Figures 17 and 18 present r.m.s. distributions measured downstream of the tee and 7-tube tube bundle of the streamwise and vertical components, respectively, of the turbulent velocity along the diameter perpendicular to the plane of the tee. The profiles measured nearest the tube bundle exit show via the peaks in these distributions the effects of the interactions between the jetting flows from the individual tubes. These profiles show a monotonic decay toward the distributions measured by Laufer which is given by the dashed line.

The basic conclusions drawn from the measurements downstream of the tee and the 7-tube tube bundle are that the profile evolution processes produced both time-averaged and turbulent velocity distributions which more closely resemble the fully developed profiles than were found downstream of the 19-tube tube bundle. Additionally, these distributions more rapidly and essentially monotonically approach the fully developed profiles as compared to the analogous processes found downstream of the 19-tube tube bundle.

4. Downstream of an Elbow and a 19-Tube Tube Bundle. Figures 19 and 20 present measurements downstream of the elbow and the 19-tube tube bundle for the time-averaged streamwise velocity component along the $\mathrm{X}$ and $\mathrm{Y}$ axes, respectively. The tube bundle which is shown in figure 2(a) is installed as shown in figure 3(b). The results show that this tube bundle does not radically alter the streamwise velocity profile from the form which exits the elbow, see [4]. Figure 19 confirms that the streamwise velocity profile is essentially symmetric about the center plane of the elbow and preserves this feature with downstream distance from the tube bundle exits as the distribution approaches that of the Bogue and Metzner profile shown via the dashed line. Figure 20 similarly shows the high speed flow occurring at the outside portion of the turn through the elbow and the slow flow near the inside of the turn. Within $26 \mathrm{D}$ from the exit of this elbow the profile is still significantly skewed relative to the fully developed distribution.

Figure 21 shows that the energetic, dual eddy flow generated by the elbow and clearly visible via the vertical velocity component along the $\mathrm{X}$ axis is reduced by this tube bundle to $2 \%$ or less just downstream of the tube bundle exit. Further downstream at the $26 \mathrm{D}$ position, the vertical velocities are below $1 \%$ of the bulk velocity.

Figures 22 and 23 present measurements of the streamwise and vertical r.m.s. components of the turbulent velocity downstream of the elbow and the 19-tube tube bundle. These profiles show turbulence levels only slightly larger than those measured by Laufer.

\section{Downstream of an Elbow and a 19-Tube Tube Bundle Installed In Two} Locations. Figures 24 and 25 present measured profiles of the streamwise velocity component along the $\mathrm{X}$ axis taken downstream of the elbow and the 19-tube tube bundle shown in figure 2 (a) installed at $Z=1.2$ and at $Z=3.8$. Figure 24 presents measurements made just downstream from the tube bundle exit and compares these with both the Bogue and Metzner profile and our reference profile measured with $200 \mathrm{D}$ upstream. These results show 
that when this tube bundle is installed at $Z=1.2$, the swirl reduction capability of this tube bundle seems to leave more distorted axial velocity profiles as compared to those at essentially the same location downstream from the tube bundle exit when the bundle is installed at $\mathrm{Z}=$ 3.8 .

Figure 25 presents results similar to those in figure 24 but taken further downstream at essentially $20 \mathrm{D}$ from the tube bundle exit. These profiles are compared to our reference profile measured with $200 \mathrm{D}$ upstream. Again, the profile measured with the tube bundle entrance positioned 3.8D from the elbow exit produces a profile 19D downstream from the tube bundle exit that closely approximates the reference distribution. However, when this tube bundle is installed so that the entrance is $1.2 \mathrm{D}$ from the elbow exit, the profile results show marked deviations from the reference profile.

Based on these results, it is concluded that both the axial vorticity distributions and the turbulent diffusion effects generated by the elbow contribute to the natural evolution of the fully developed pipeflows from the flow patterns which exit the elbow. When the axial vorticity distributions produced by the elbow are reduced by the presence of the 19-tube tube bundle installed near the elbow exit, the resulting profile evolution is different and slower as compared to the situation with the tube bundle installed 2.6D downstream.

FLOWMETER PERFORMANCE IN SELECTED NON-IDEAL INSTALLATION CONDITIONS

1. Orifice and Turbine Meter Downstream of The Reducer. Figures 26-28 present results for orifice meters downstream of the reducer shown in figure 1 (d) for a range of beta ratio and a succession of installation positions. These results span a turndown of 3 for each of these beta ratios and the entire Reynolds number range is from 15,000 to 100,000 . The ordinate in each of these figures is the percentage shift at each flowrate, in discharge coefficient relative to that obtained for the reference condition. These results show that for all beta ratios, when the orifice meter is installed near the reducer the discharge coefficient is shifted negatively. The amount of negative shift is dependent upon beta ratio and ranges from about $-0.15 \%$ for the small beta of 0.363 to $-1.7 \%$ for the largest beta of 0.75 .

When the orifice meter to reducer exit distance is increased, these negative shifts diminish and become zero around the downstream position of 11-13D from the reducer. However, with increased downstream distance, orifice discharge coefficients are shifted positively relative to reference values. These positive shifts appear, from these results, to be maxima at the installation position 20D downstream from the reducer. These maxima also appear to be dependent upon beta ratio with the smallest shift of about $+0.1 \%$ occurring for beta $=0.363$ and the largest of about $+0.5 \%$ for beta $=0.75$. For orifice meters installed further than $20 \mathrm{D}$ downstream of the reducer, the results in figures 26-28 show that the positive shifts in discharge coefficient decrease, so that deviations from reference condition values are essentially less than $0.1 \%$ for all of these betas at and beyond the 55D location.

Figure 29 presents results obtained for the selected turbine meter installed downstream of the reducer. The ordinate is the percentage shift in meter factor at each flowrate taken relative to our reference condition. The results, taken over the Reynolds number range from 40,000 to 100,000 indicate that this meter is not affected by the pipeflows exiting this reducer. It is therefore concluded that the geometry of this turbine design is capable of successfully averaging over the flow patterns presented in figures 4 and 5 and producing a meter factor that is essentially the reference value in the installation conditions. 
2. Orifice and Turbine Meter Downstream of an Elbow and a 19-Tube Tube Bundle. When the 19-tube tube bundle which is shown in figure 2(a) is installed 1.2D downstream from an elbow as shown in figure 3(b), the performances of different orifice meters installed in different positions downstream of the tube bundle exit are as shown in figures 30-32. The ordinate is the discharge coefficient shift, at each flowrate, relative to the reference value. The range of Reynolds number spanned is 15,000 to 100,000 ; the beta ratio range is 0.363 to 0.75 and each meter is tested over a 3 to 1 turndown. As noted previously, discharge coefficient shifts are negative for installation positions near the tube bundle with largest shifts for largest beta ratios. For meter installations more distant from this tube bundle, the negative shifts diminish, become zero, and proceed to shift positively. However, the maximum value of the positive shift is only about $+0.1 \%$ and this value pertains to essentially all three of the beta ratios and it occurs for meter installation position about 25D downstream of the tube bundle exit.

When the turbine meter is tested downstream of the elbow and the 19-tube tube bundle installed as shown in figure 3(b), results are as given in figure 33 . Here, the meter factor shift is $-0.05 \%$ for installation position $2 \mathrm{D}$ downstream of the tube bundle exit and for further positions, this shift approaches and reaches zero for the position about $8 \mathrm{D}$ downstream. Beyond this position, the meter factor attains positive shifts which reach a maximum of $+0.05 \%$ at the $14 \mathrm{D}$ position downstream. At and beyond the $37 \mathrm{D}$ position, this meter shows no further shift relative to the reference value.

3. Orifice Meter Downstream of an Elbow with Closely Installed 19-Tube Tube Bundle with 5D Pipe Downstream. Figure 34 presents orifice meter test results obtained for installations downstream of the single elbow with the 19-tube tube bundle at the $1.2 \mathrm{D}$ position shown in figure $3(\mathrm{~b})$ and $5 D$ pipe length separating the orifice plate and a downstream elbow. Comparing these results with those shown in figure 31 indicates that the 5D pipe length separating the orifice plate and the downstream elbow is apparently adequate to remove any noticeable perturbation to the orifice performance obtained when a much longer length of pipe $(\sim 15 D)$ separated the orifice plate and the downstream elbow.

\section{METER PERFORMANCE VARIATIONS VERSUS INSTALLATION POSITION FROM SELECTED NON-IDEAL PIPING AND TUBE BUNDLE ARRANGEMENTS. The previously described results are presented in a different format in the following section. This format will facilitate the production of installation recommendations for both orifice and turbine meters.}

1. Orifice Meter. Figure 35 presents data obtained for the beta $=0.363$ meter installed at different downstream distances from the reducer. The ordinate is the percentage change in discharge coefficient relative to the reference value at each flowrate. Three conditions are shown. The first is the mean value of discharge coefficient for the respective installation obtained over the Reynolds range 15,000 to 45,000 . The second is the value for the lowest flowrate, $\operatorname{Re}=15,000$; these data are plotted with error bars denoting a standard deviation of all values taken at each position. The third value is that for the highest flowrate, $\mathrm{Re}=$ 45,000 with error bars as described above. These results indicate that for this meter, the discharge coefficient is within $\pm 0.25 \%$ of the reference value for all installation positions downstream of this reducer. It is also noted that the largest negative shifts occur for the highest flowrate while the largest positive shifts occur for the lowest flowrate.

Figure 36 presents results obtained for the different meter geometries tested downstream of this reducer at the same positions and for the same flowrate, $\operatorname{Re}=45,000$. These show sizeable differences that depend upon beta ratio. For installations near the reducer where all of the discharge coefficients are shifted negatively with respect to the reference values, the 
beta $=0.75$ meter has a deviation that is about eight $(8)$ times that for the beta $=0.363$ meter. These meters indicate that the "cross-over" position where discharge coefficient shifts change sign from negative to positive is about $11 \mathrm{D}$ from the exit of the reducer. Beyond this location where the discharge coefficients become positive, the largest beta ratio has the largest shift reaching a maximum of $+0.5 \%$ at the $20 \mathrm{D}$ location.

Figure 37 presents orifice performance characteristics for different beta ratios at the same flowrate, $\mathrm{Re}=45,000$ at different downstream positions from a single elbow and a 19-tube tube bundle. Results are shown versus downstream distance, $\mathrm{C}$ in diameters, from the exit plane of the tube bundle. This tube bundle is installed so that its entrance plane is 1.2D downstream from the exit of the single elbow. The symbols plotted are the mean values of the discharge coefficient shifts in percentages relative to reference values. Error bars denote one standard deviation of the repeated readings about the mean value. These results show more clearly than in figures 30-32 the dependence of the orifice characteristics for the three meters at the same flowrate. Significant negative shifts in discharge coefficient are noted especially for the larger beta ratios, magnitudes of these shifts diminish markedly with increasing axial separation, $C$ between the orifice plate and the tube bundle exit. The different beta ratio meters achieve zero shift positions that are different with the beta $=0.363$ meter attaining a zero shift position of about $C=11 \mathrm{D}$. Beyond this position the shift can be considered essentially zero. The beta $=0.50$ and the beta $=0.75$ meters attain zero shift positions, respectively, at distances of about 19D and 25D. Again, beyond these distances, shifts can be considered essentially zero.

Figure 38 presents orifice performance characteristics analogous to those of figure 37 except the downstream pipe length was different. The data presented in figure 38 was taken for an orifice installation where a 5D length of pipe separated the orifice plate from a downstream elbow. In all other tests, a long pipe length which exceeded $15 \mathrm{D}$ and was varied according to meter position separated the orifice plates from the downstream elbow. The reproduceability of the results is considered very good. The conclusion is again drawn that for these conditions the downstream pipe length of $5 \mathrm{D}$ is adequate to prevent any effects propagating upstream from the downstream elbow to affect these orifice meters. It is noted that the separation distances between orifice plates and the exit plane of the tube bundles to attain the zero shift conditions are essentially the same as those observed in figure 37.

If one places a tolerance of $\pm 0.25 \%$ about the reference orifice discharge coefficients, a table of recommended lengths to attain this level of performance for these fluid and flow conditions can be generated from these data, see Table 1.

In contrast with the minimal distances tabulated above for the present fluid and flow conditions, the corresponding minimal lengths recommended by AGA Report No. 3 [12] for orifice installations downstream of the reducer are $6,7.5$, and 13.5 for beta ratios $0.363,0.50$, and 0.75 , respectively. It is concluded therefore that based on the results of the present study, the orifice installation recommendations are conservative in AGA-3. In ASME MFC-3M the installation recommendations are for a $2 \mathrm{D}$ to $\mathrm{D}$ reducer 5,5 , and 11 diameters respectively for betas $=0.36,0.50$, and 0.75 . It is concluded here that the lowest and highest beta ratios are again conservative compared to present results, but the beta $=0.5$ recommendation appears insufficient to produce the $\pm 0.25 \%$ tolerance.

2. Turbine Meter. Figure 39 presents results for the turbine meter installed downstream of two configurations for $\mathrm{Re}=100,000$. The first is the reducer for which results indicate that this meter is essentially unaffected by the flows from this reducer. The second configuration is the single elbow and the 19 tube tube bundle installed as shown in figure 3(a). Again, it is noted that this meter is shifted less than $\pm 0.05 \%$ from the reference values for all 
installation positions tested. Perhaps if this meter had been tested within 5D from the elbow, a shift of about $-0.1 \%$ might have occurred judging from an extrapolation of these results.

\section{TABLE 1. INSTALLATION LENGTHS (IN DIAMETERS) FOR THE RESPECTIVE TEST CONDITIONS $(\mathrm{RE}=45,000)$. CRITERIA IS $\pm 0.25 \%$ OF IDEAL VALUES.}

\begin{tabular}{||l|c|c|c|}
\hline \multirow{2}{*}{ Configuration } & \multicolumn{3}{|c|}{ Beta Ratio } \\
\cline { 2 - 4 } & $\mathbf{0 . 3 6 3}$ & $\mathbf{0 . 5 0}$ & $\mathbf{0 . 7 5}$ \\
\hline Reducer & 2 & 7 & 9 \\
\hline $\begin{array}{l}\text { Single Elbow } \\
\text { w/19 Tube Bundle } \\
\text { at Z = 1.2 }\end{array}$ & 4 & 12 & 20 \\
\hline $\begin{array}{l}\text { Single Elbow } \\
\text { w/19 Tube Bundle } \\
\text { at Z = 1.2 and 5 D } \\
\text { downstream }\end{array}$ & 2 & 12 & 17 \\
\hline
\end{tabular}

\section{CONCLUSIONS}

The velocity profile measurements made downstream from this reducer for the selected fluid and flow conditions indicate that the dissipation of the reducer effects does not occur with a monotonic progression of the mean axial velocity profile to that for the ideal distribution. Instead, the profile overshoots the ideal distribution to produce a significant core of fast flow in the center of the pipeflow and this situation prevails along the length of the pipe from about the $15 \mathrm{D}$ point downstream of the reducer to about the $30 \mathrm{D}$ point. Meters such as orifice plates that can be sensitive to such profile anomalies can be expected to show such effects.

The wide range of orifice meters tested in these reducer effects show that there is a pronounced beta ratio dependence in the orifice characteristics. Low beta ratios $(\sim 0.36)$ are hardly affected; large ratios $(0.75)$ show significant deviations from ideal discharge coefficient characteristics.

Turbine meter characteristics, at least for the specific meter design tested, do not seem to be so radically affected by the pipeflows downstream from the reducer as compared to the orifice meters tested. The turbine meter tested could, for our conditions, be installed immediately downstream from the reducer or at any further downstream location and the meter factor is the ideal value.

The velocity profile measurements downstream from the tee used as an elbow show that secondary flows similar to those produced by the single elbow are generated in the downstream pipe. Additionally, these flows are accompanied by levels of turbulence that are higher than those from the elbow. The net results are that the flow effects from the tee dissipate more rapidly than those from the elbow. Data for the conditions tested show that the dual-eddy swirl patterns produced by the tee have dissipated within about 6 diameters from the exit of the tee. However, the tee-produced disturbances to the axial velocity profiles persist to beyond the 20D point downstream. 
When a 7-tube tube bundle is installed downstream of the tee used as an elbow, the axial velocity profile is efficiently and effectively changed to closely approximate that for the reference condition. This conditioning occurs within 10-15D from the exit plane of the tube bundle. It therefore seems appropriate to examine the capabilities of this 7-tube tube bundle in geometrically scaled flows at higher Reynolds number. As well, it seems appropriate to assess the capabilities of this device in other flows such as single and double elbows out of plane, etc.

The effectiveness of the 19-tube tube bundle was assessed in an installation position close to the exit of the single elbow. Here, with the tube bundle entrance at $1.2 \mathrm{D}$ downstream from the elbow exit, it was found to be not as effective as when installed 3.8D from the exit. It is concluded, therefore, that when installed in the more upstream position, it eliminates the dual eddy swirl pattern produced by the elbow thus leaving only the residual turbulent mixing and dissipation to evolve the reference profile. On the other hand, when installed downstream, the dual eddies are eliminated later but before they apparently are removed they contribute significantly to the profile evolution processes.

When the pipe lengths that separate our orifice plates from a downstream elbow are shortened to $5 \mathrm{D}$, our orifice meter characteristics for installations downstream of the single elbow and a 19-tube tube bundle show that no change occurred. It is therefore concluded that, for the conditions tested, a 5D or longer pipe length is adequate to separate any upstream effects on beta $=0.5$ orifice plates due to a downstream eibow.

Based upon the orifice meter performance characteristics determined for the conditions tested, tabulations of recommended minimal installation lengths can be done according to selected tolerance levels. These lengths, selected for a tolerance level of $\pm 0.25 \%$ can be compared to those quoted in such standards as AGA-3 or ASME MFC-3M the conclusions are that the AGA lengths are all larger than present results. The ASME recommendations are also found to be conservative for the small and large beta ratios, however, the beta $=0.50$ recommendation is found to be too small in comparison with present results.

It is therefore concluded from these results that more work needs to be done to improve U.S. metering installation recommendations.

\section{ACKNOWLEDGMENT}

The authors acknowledge the technical assistance for these experiments provided by Mr. B. L. Shomaker and the secretarial efforts of Mrs. G. M. Kline in preparing this report. 


\section{REFERENCES}

1. Mattingly, G.E. and Yeh, T.T., NIST's Industry-Government Consortium Research Program on Flowmeter Installation Effects: Report of Results for the Research Period Feb-Dec. 1990: Tee Used As An Elbow (In review).

2. Mattingly, G.E. and Yeh, T.T., NIST's Industry-Government Consortium Research Program on Flowmeter Installation Effects: Report of Results for the Research Period May 1989 - Feb. 1990: Tube Bundle (In review).

3. Mattingly, G.E. and Yeh, T.T., NIST's Industry-Government Consortium Research Program on Flowmeter Installation Effects: Report of Results for the Research Period Nov. 1988 - May 1989, NISTIR 4310, Apr. 1990.

4. Mattingly, G.E. and Yeh, T.T., NIST's Industry-Government Consortium Research Program on Flowmeter Installation Effects: Report of Results for the Research Period Jan. 1988 - Oct. 1988, NISTIR-89.

5. Mattingly, G.E. and Yeh, T.T., NIST's Industry-Government Consortium Research Program on Flowmeter Installation Effects: Report of Results for the Research Period June - December 1987. NISTIR-88-3898, Sept. 1988.

6. ASME MFC-10M, Method for Establishing Installation Effects on Flowmeter, Amer. Soc. of Mech. Engr., Nov. 1988, New York, NY.

7. Yeh, T.T. and Mattingly, G.E., Secondary Flows in Pipes, (In NIST review for planned submission to ASME Journal of Fluid Engineering).

8. Mattingly, G.E. and Yeh, T.T., Robertson, B. and Kothari, K., NBS Research on InSitu Flowmeter Installations, Procs, AGA Distribution and Transmission Confr. Las Vegas NV, May 1987.

9. Mattingly, G.E. and Yeh, T.T., Effects of Non-Ideal Pipeflows and Tube Bundles on Orifice and Turbine Meters, Flow Measurement and Instrumentation Journal, Special Issue on Flowmeter Installation Effects, Butterworth Publ., Guildford, U.K., Feb. 1991, pp. 1-19.

10. Bogue, D.C. and Metzner, A.B., Velocity Profiles in Turbulent Pipe Flow, I\&EC Fundamentals Vol. 2, No. 2, May 1963, pp 143-9.

11. Laufer, J., The Structure of Turbulence in Fully Developed Pipe Flow, NBS Rept. 1974, Sept. 1952. Alternatively see Hinze, J.O., Turbulence, McGraw-Hill, New York (1959) (Laufer's data in chapter 7).

12. American Gas Association, Report No. 3 Orifice Metering of Natural Gas, ANSI/API2530, 1978 AGA, Arlington, VA 22209.

13. ASME, MFC-3M, Measurement of Fluid Flow in Pipes Using Orifice Nozzle, and Venturi, ASME 1985 New York, NY 10017. 
$\left(\begin{array}{ll}Y & \\ Z & \text { (a) Single Elbow }\end{array}\right.$

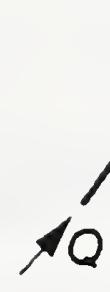

(b) Double Elbows
Out of Plane

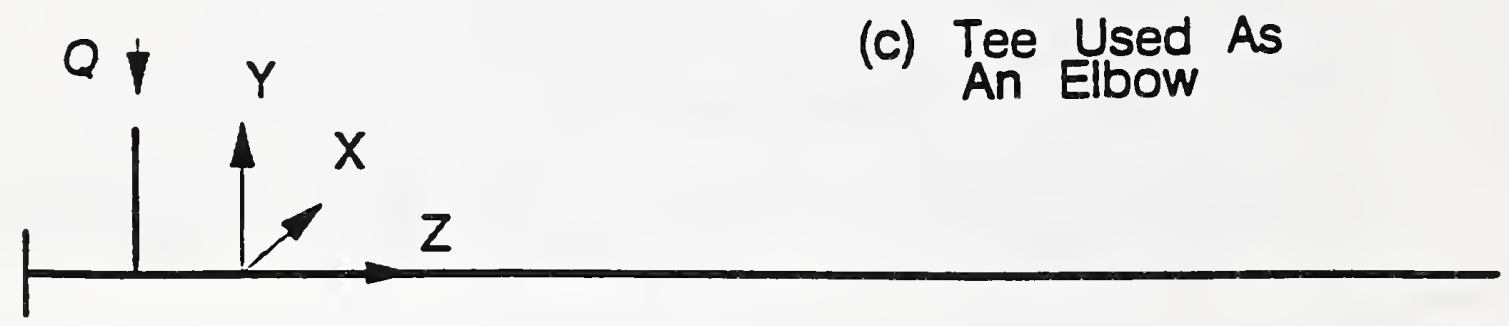

(d) Reducer

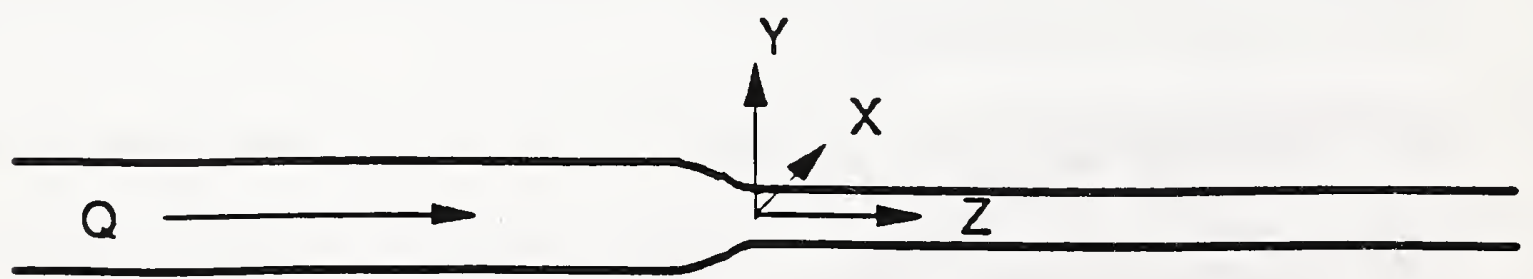

Figure 1 Sketches of Piping Arrangements and Coordinate Systems. 


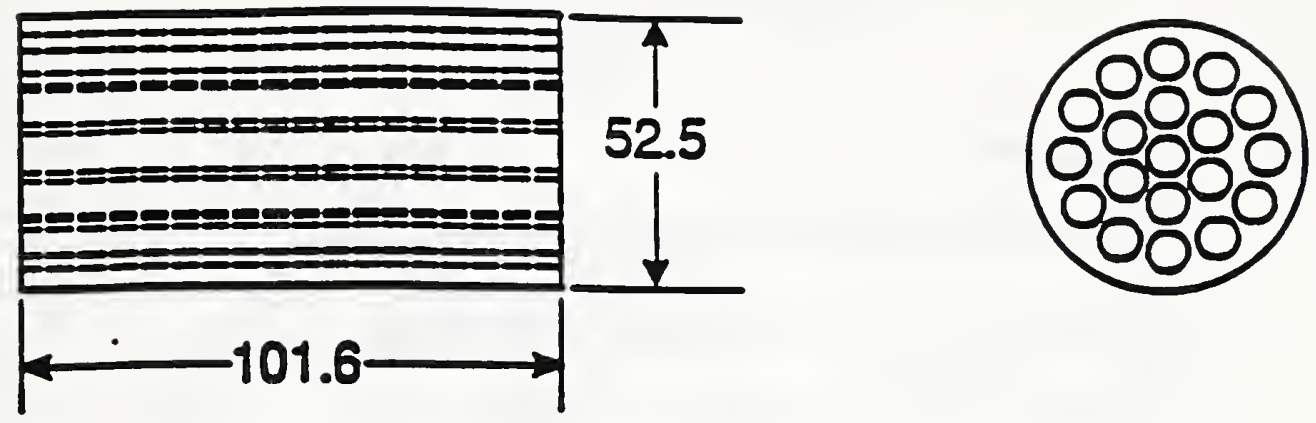

(a) 19 tube

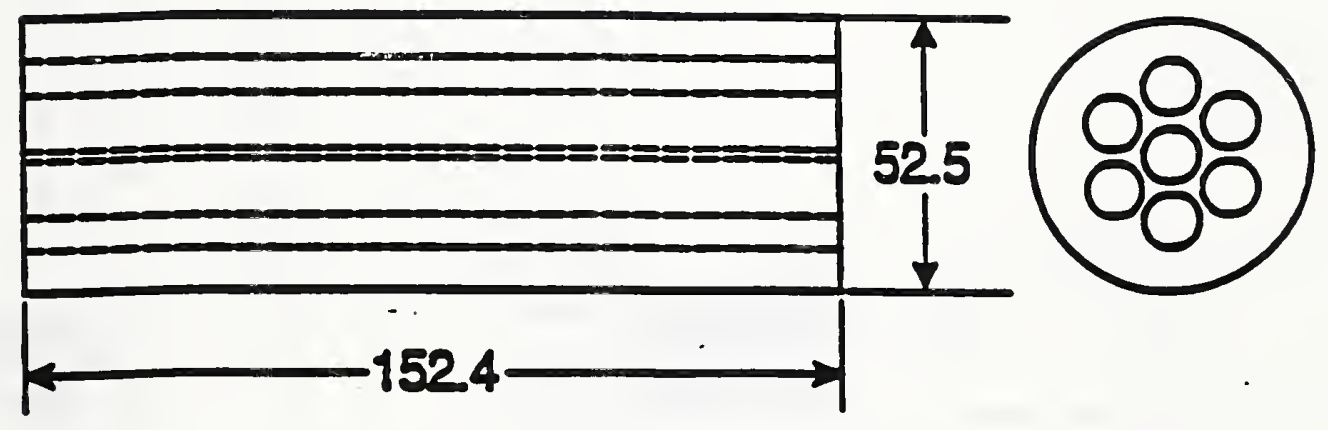

(b) 7 tube

Figure 2 Sketches of Tube Bundles: and (b) 7 Tube Unit Dimensions

(a) 19 Tube, Concentric Arrangement are in millimeters. 

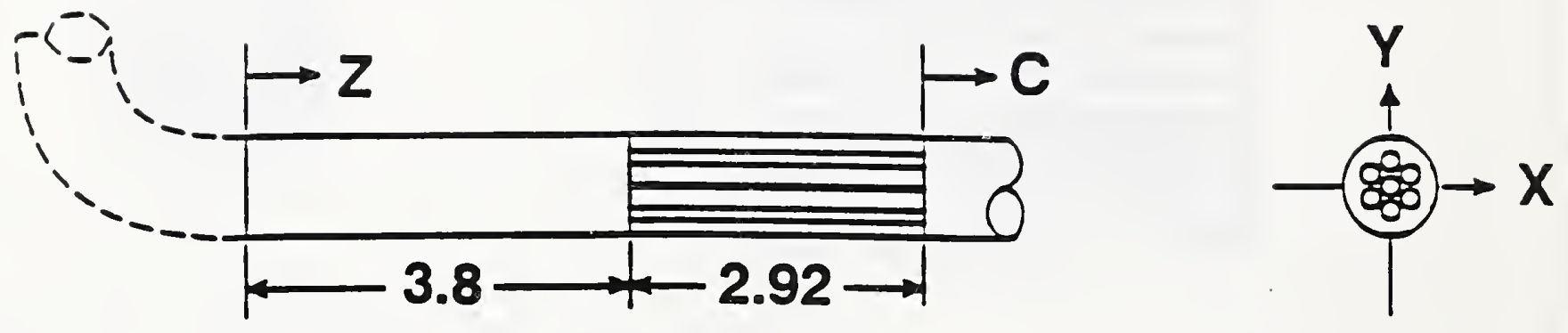

(a) 7 tube
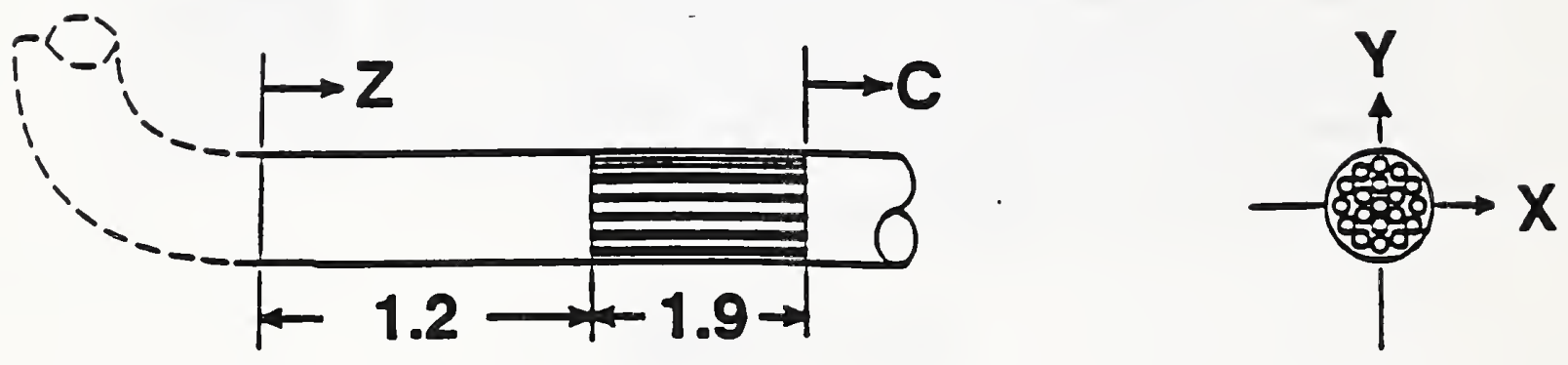

(b) 19 tube Figure 3
Elements. Sketches of Tube Bundle Installations Downstream of Pipeline
Pipeline Elements Tested. Elbow, Shown Dashed, Exemplifies all of the 


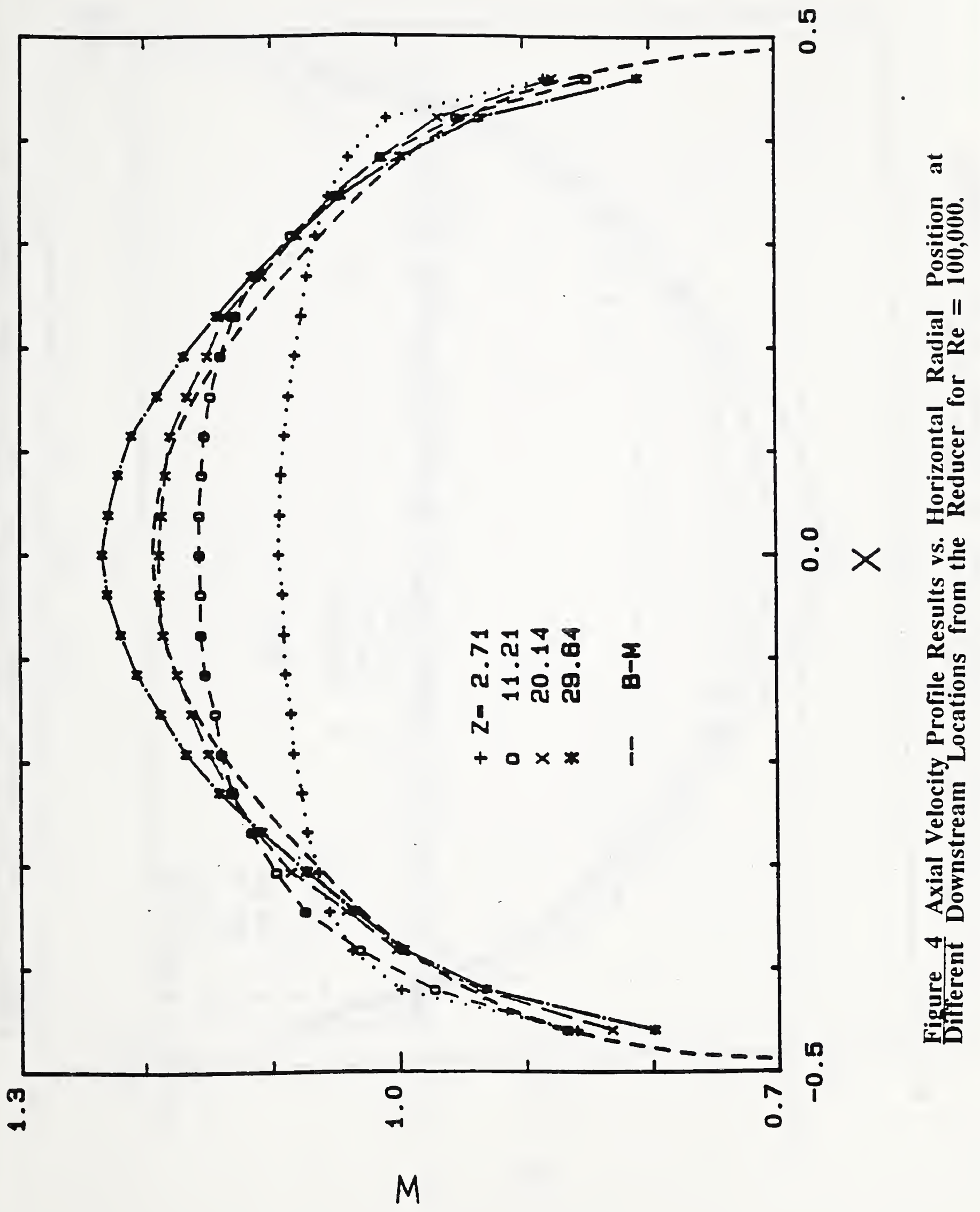




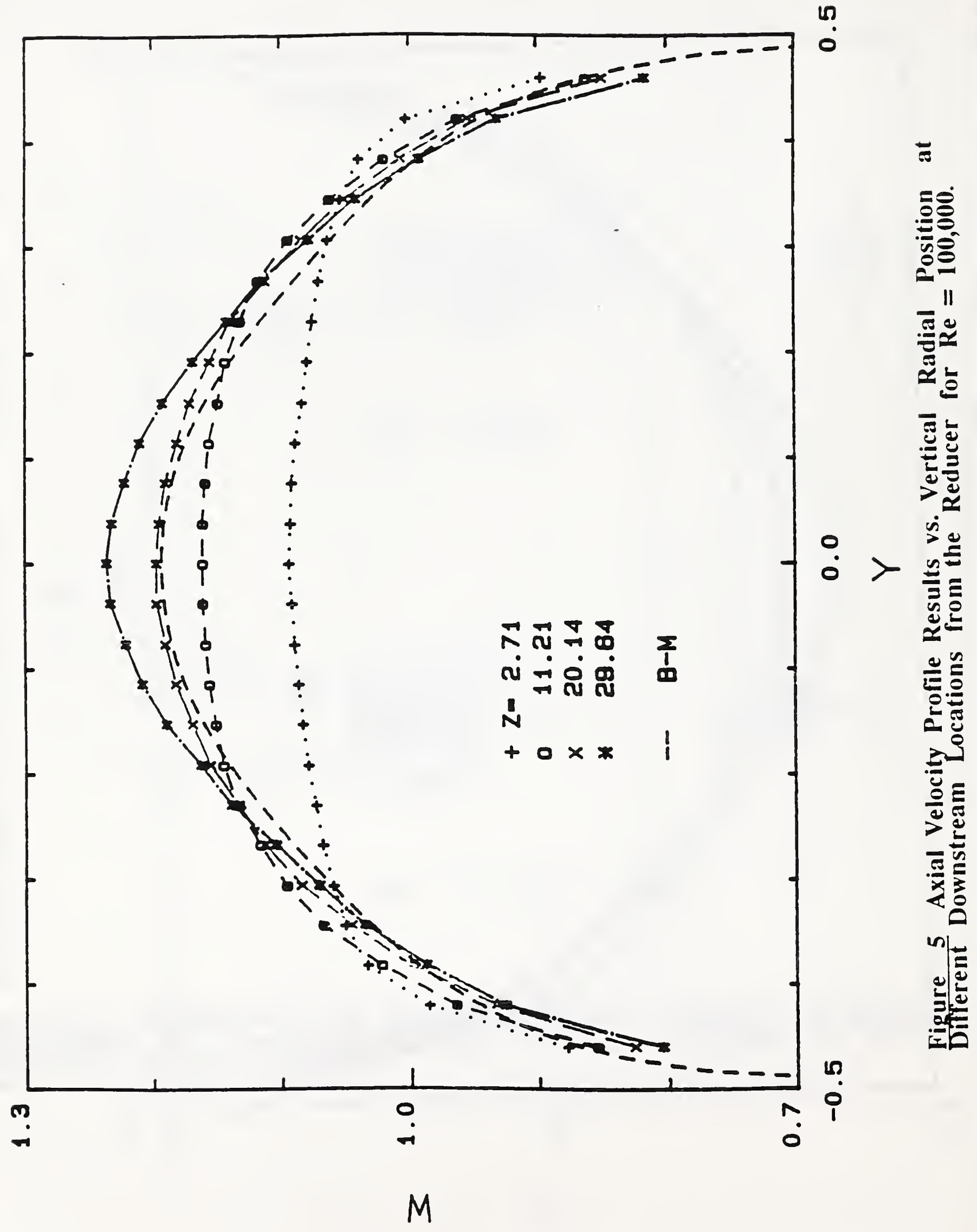




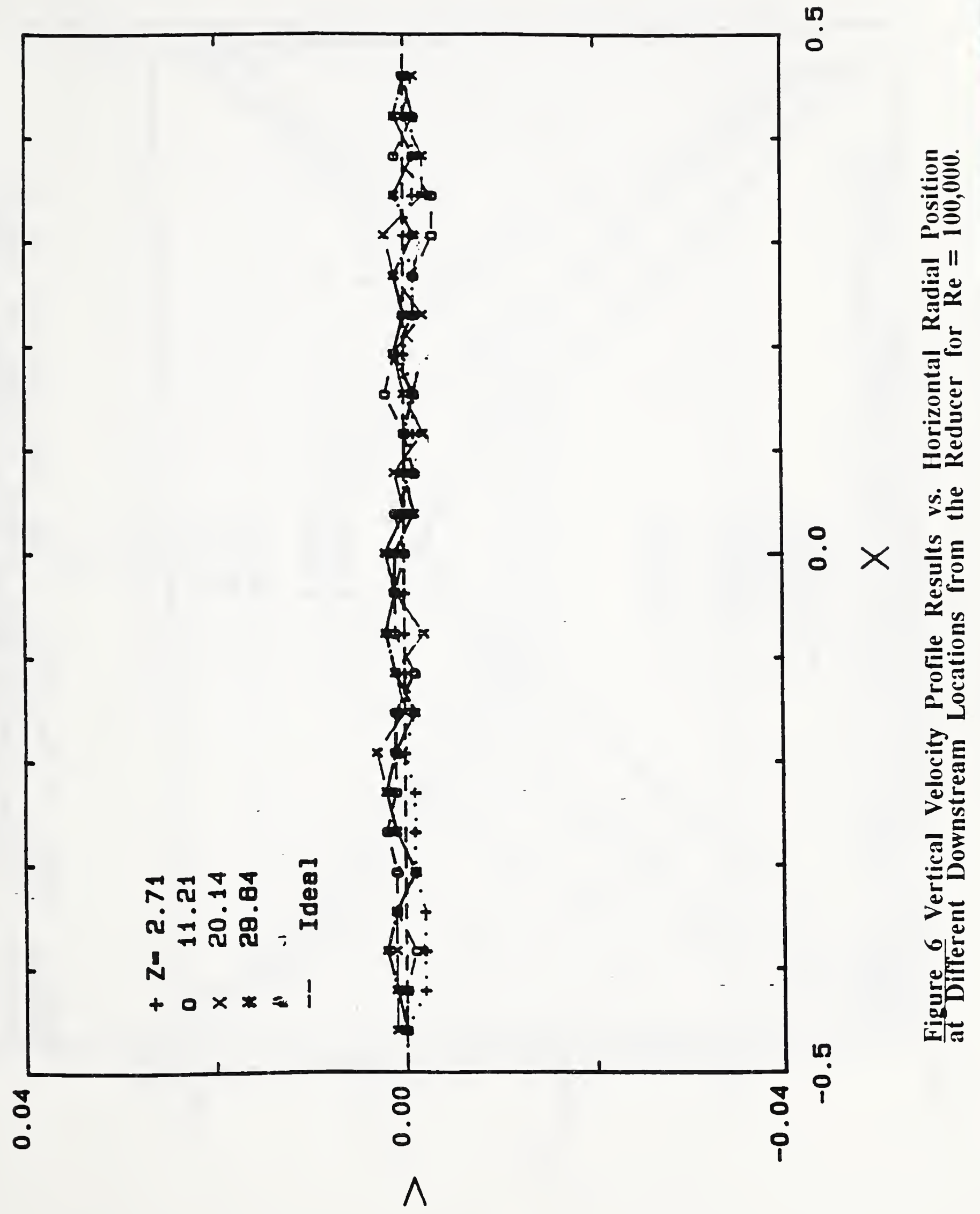




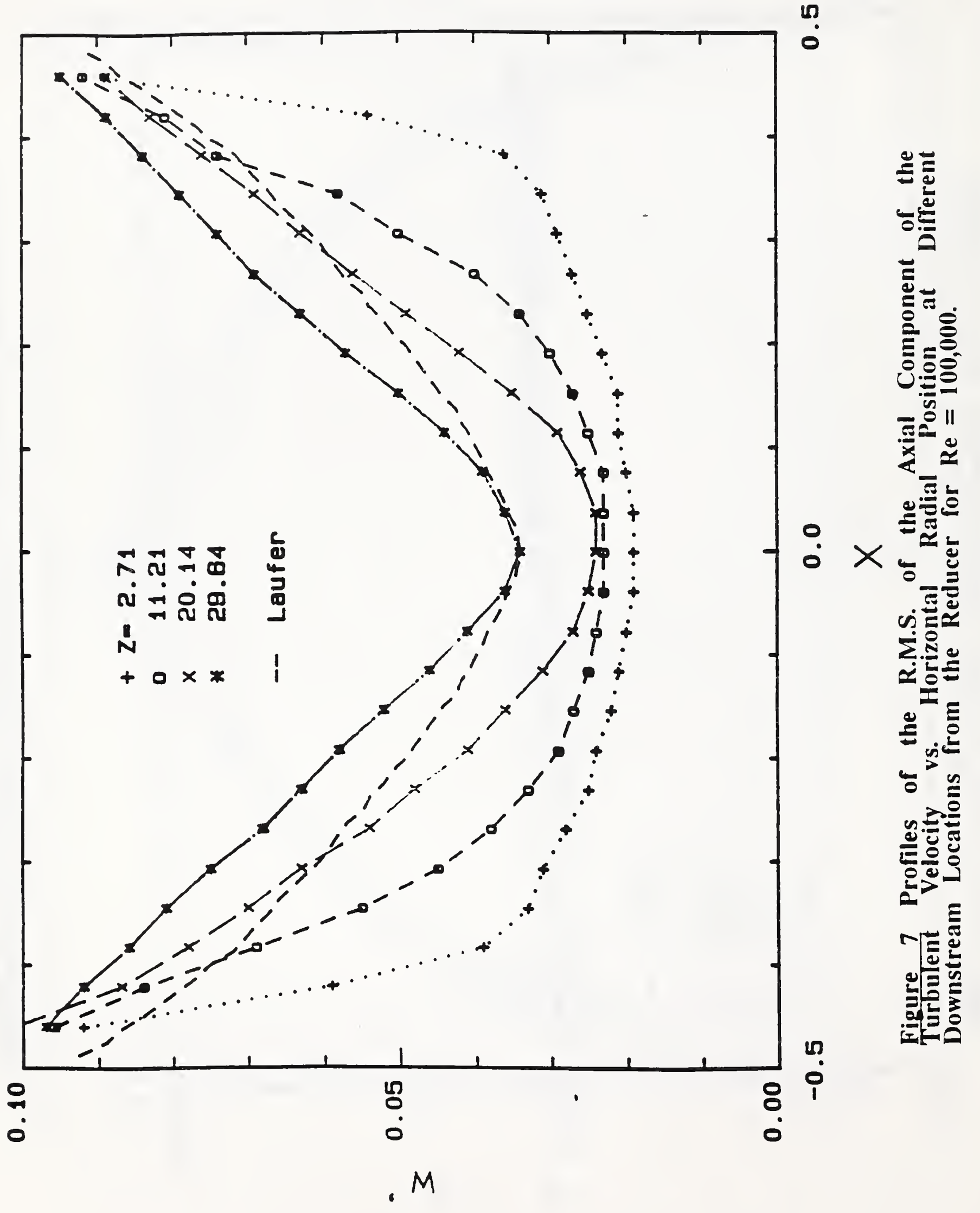




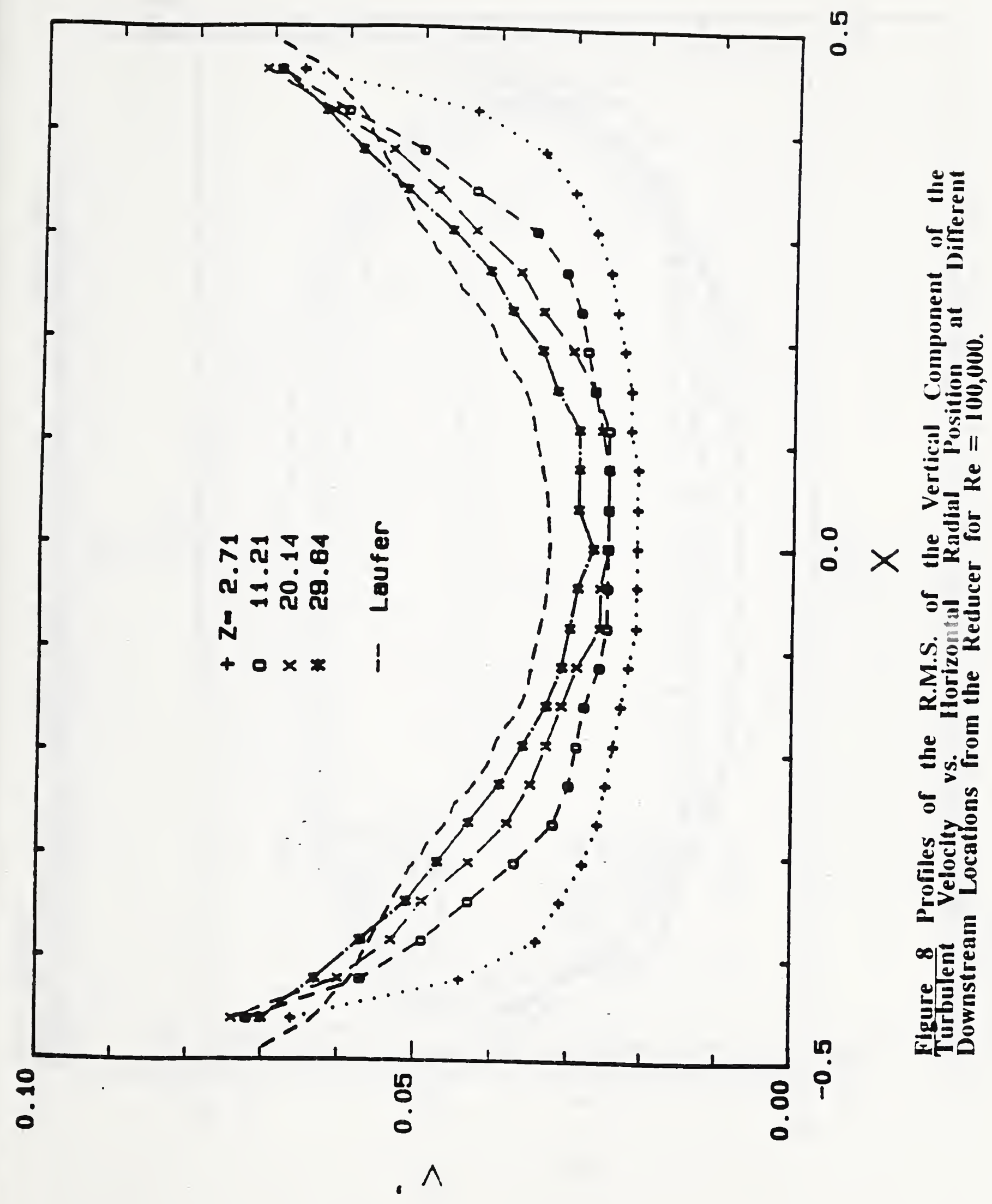




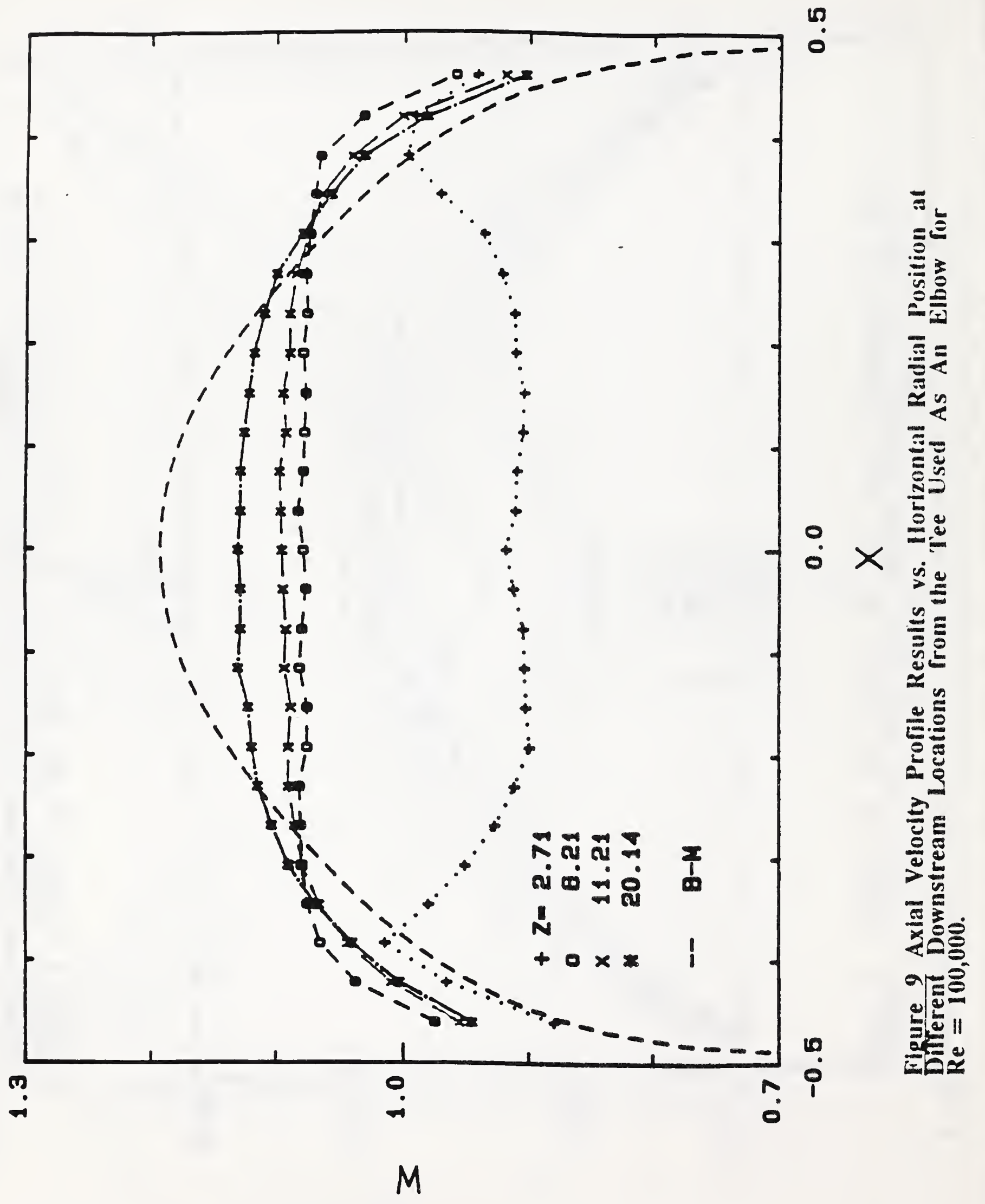




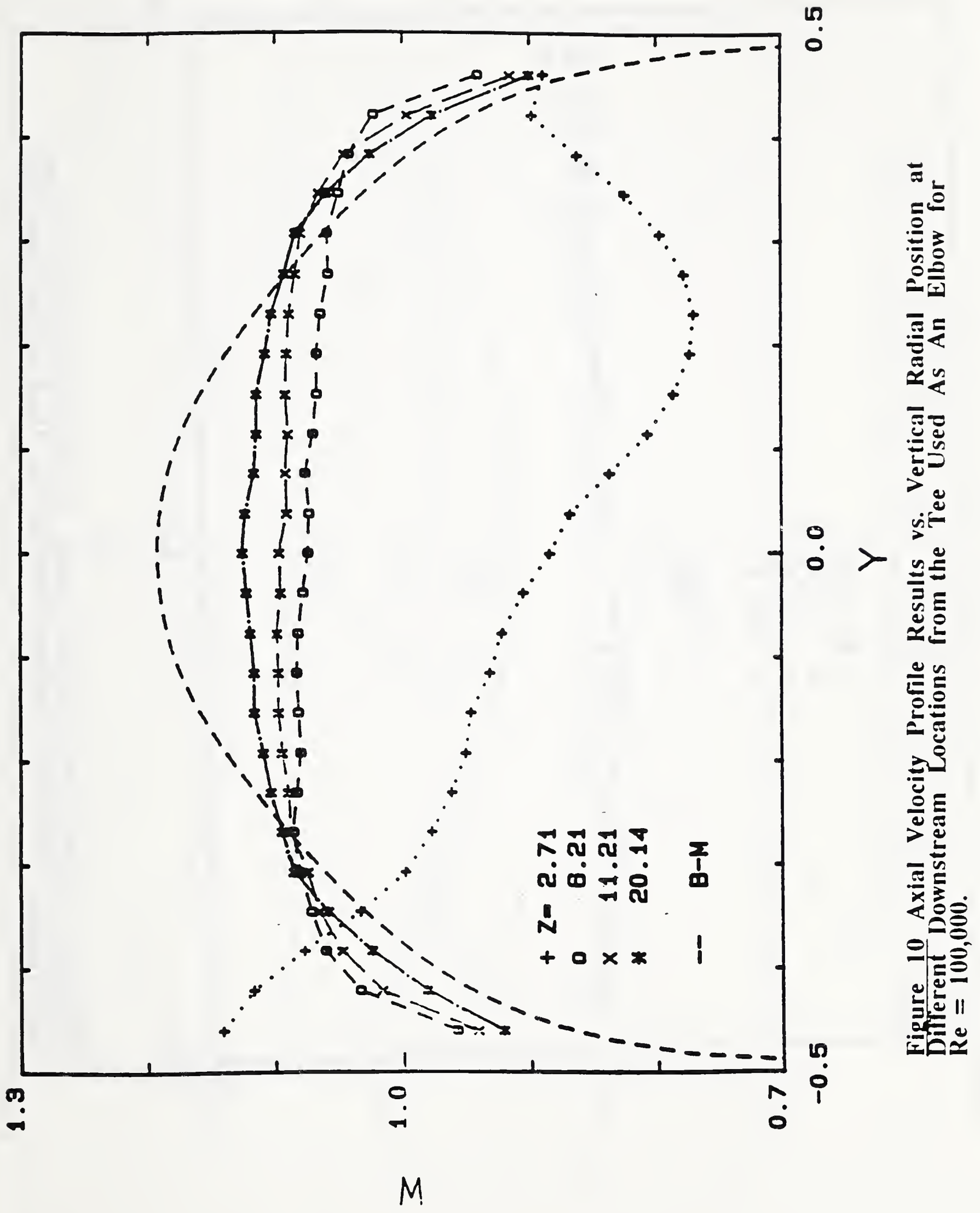


12

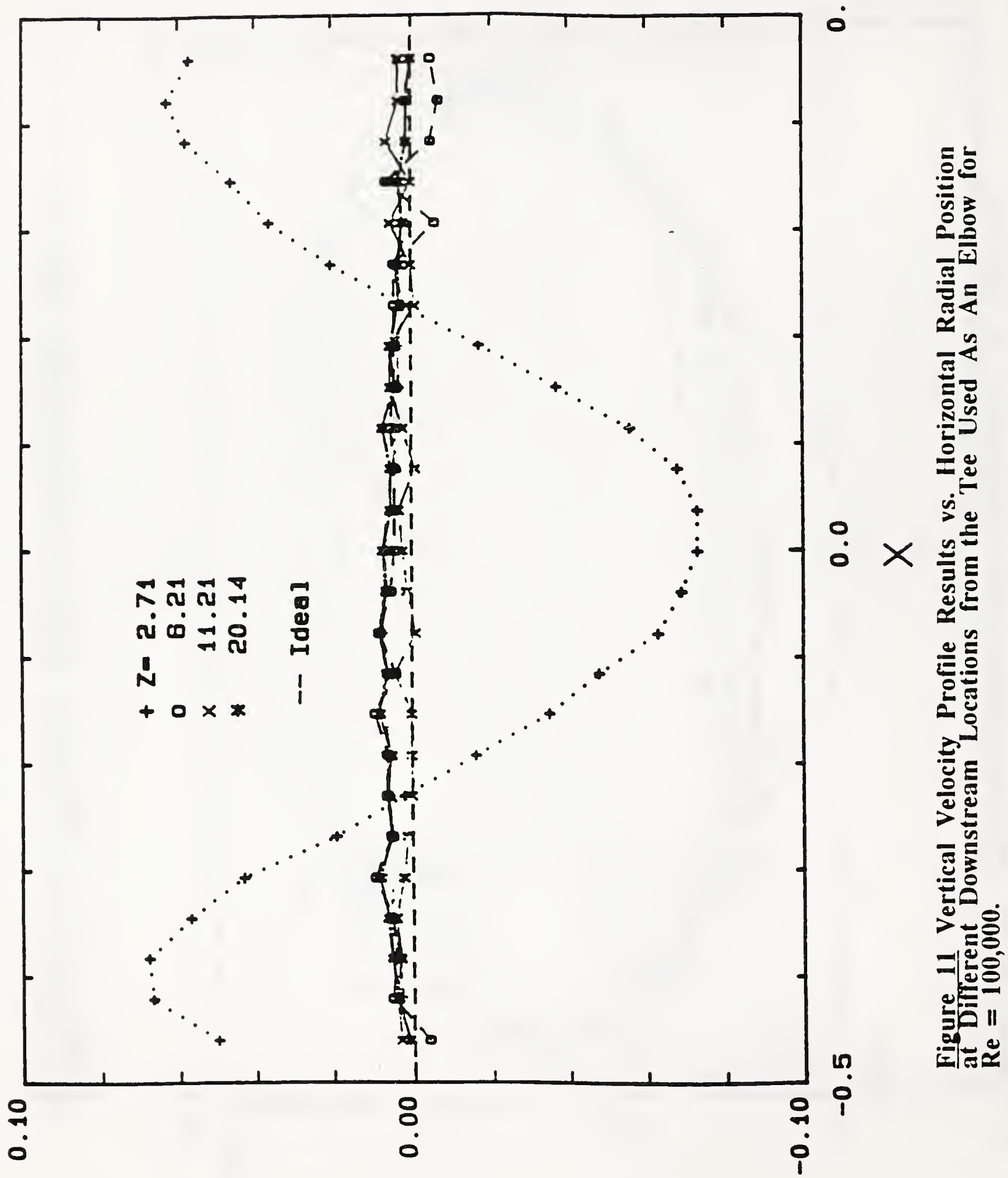

$\wedge$ 


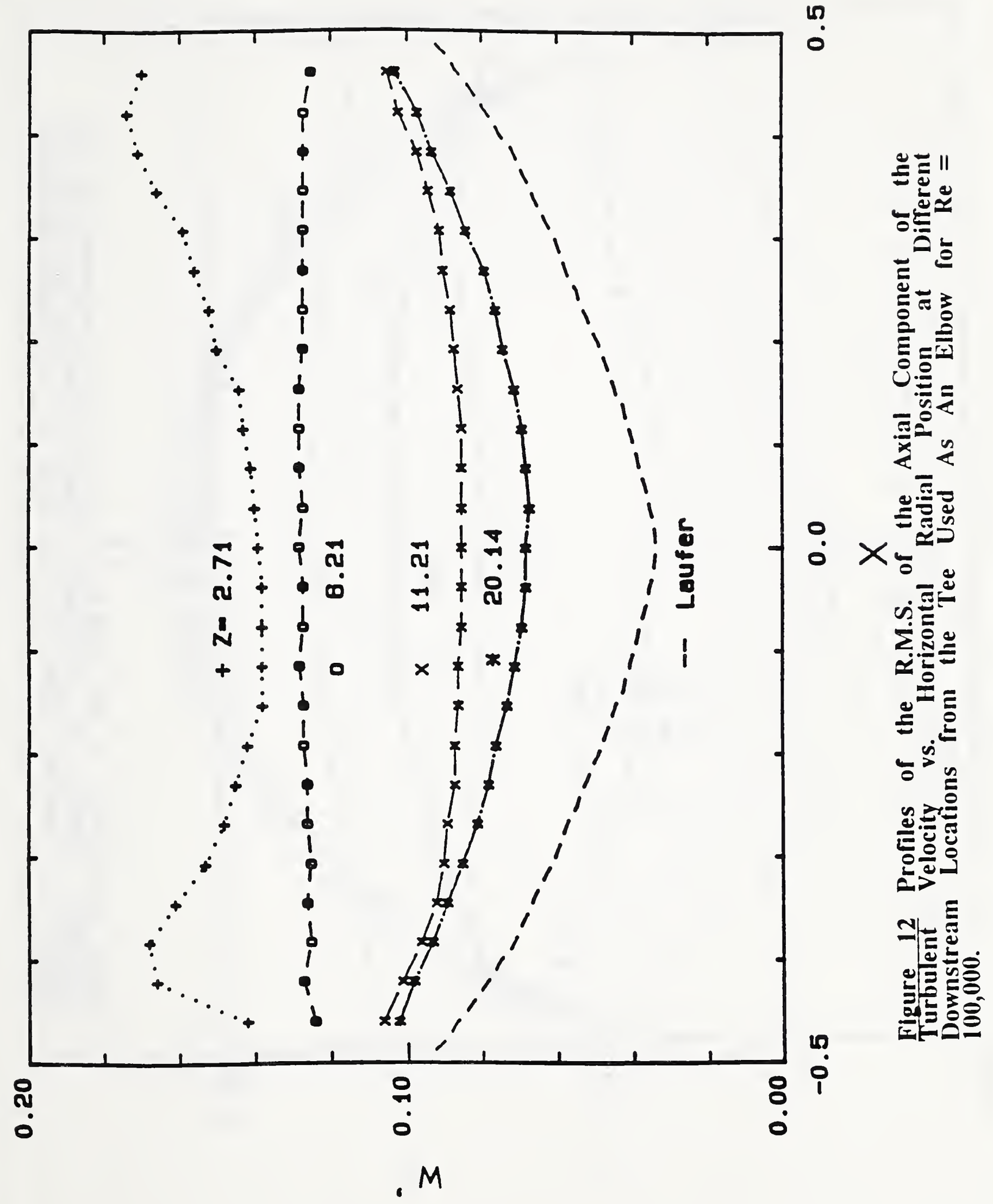




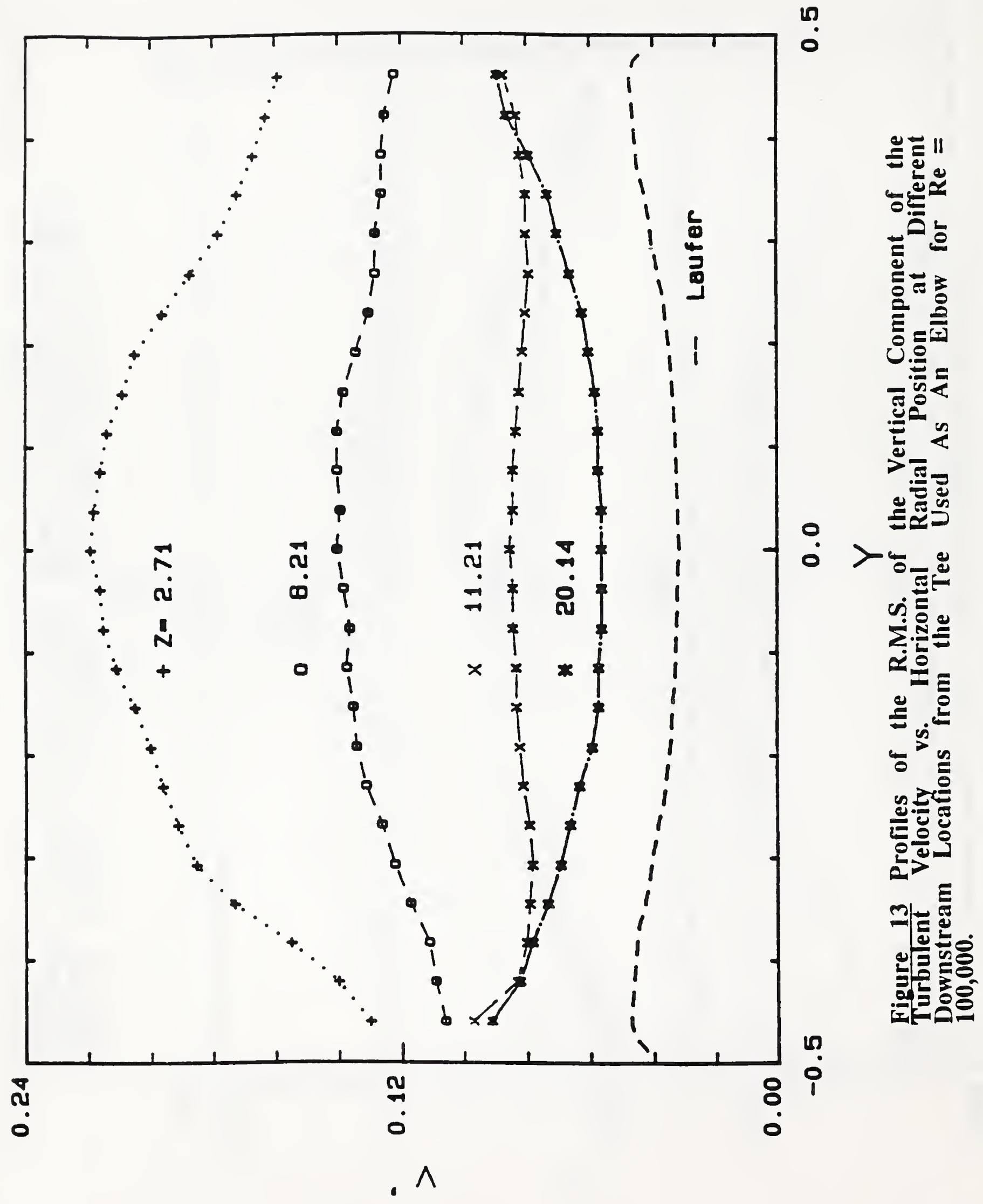




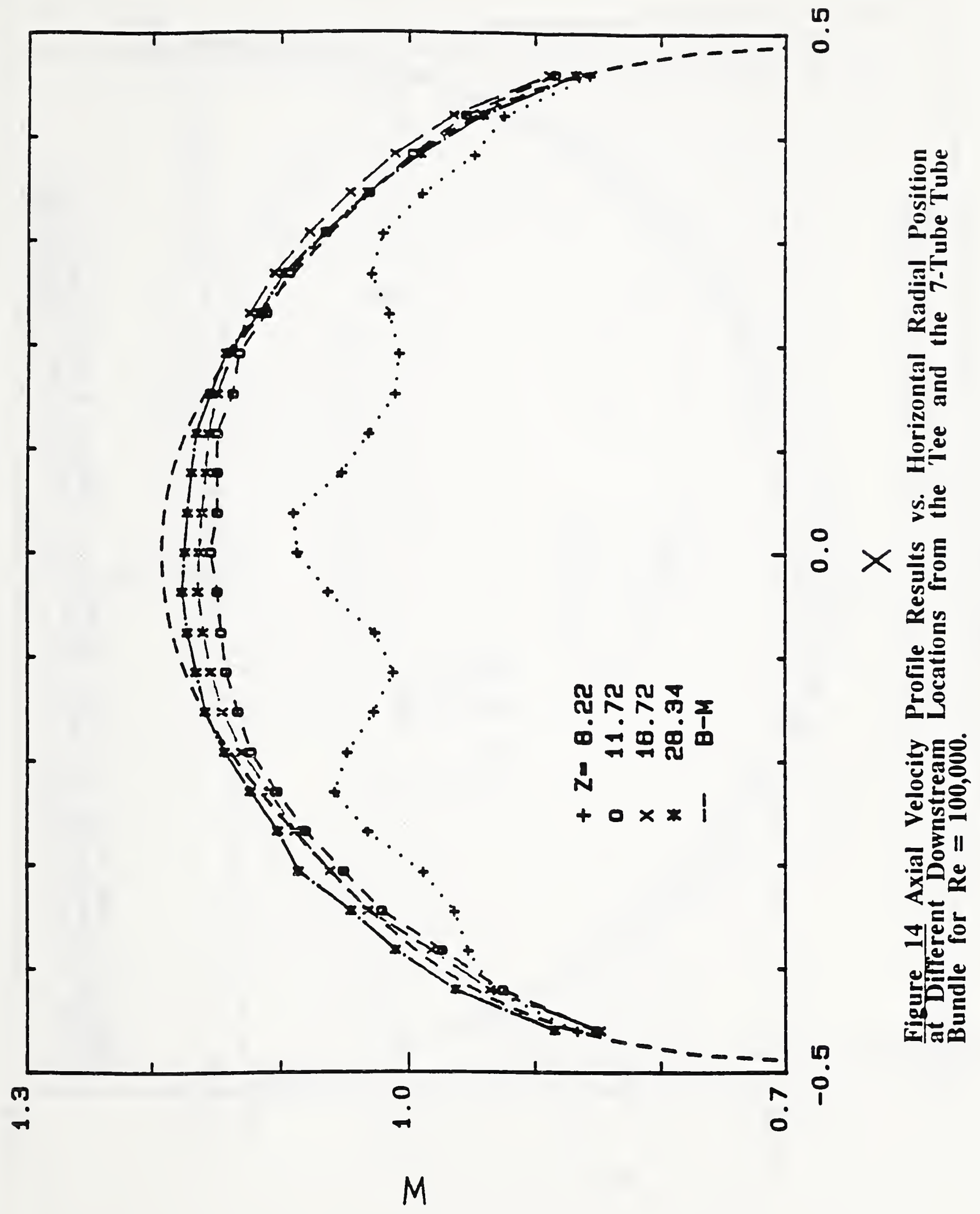




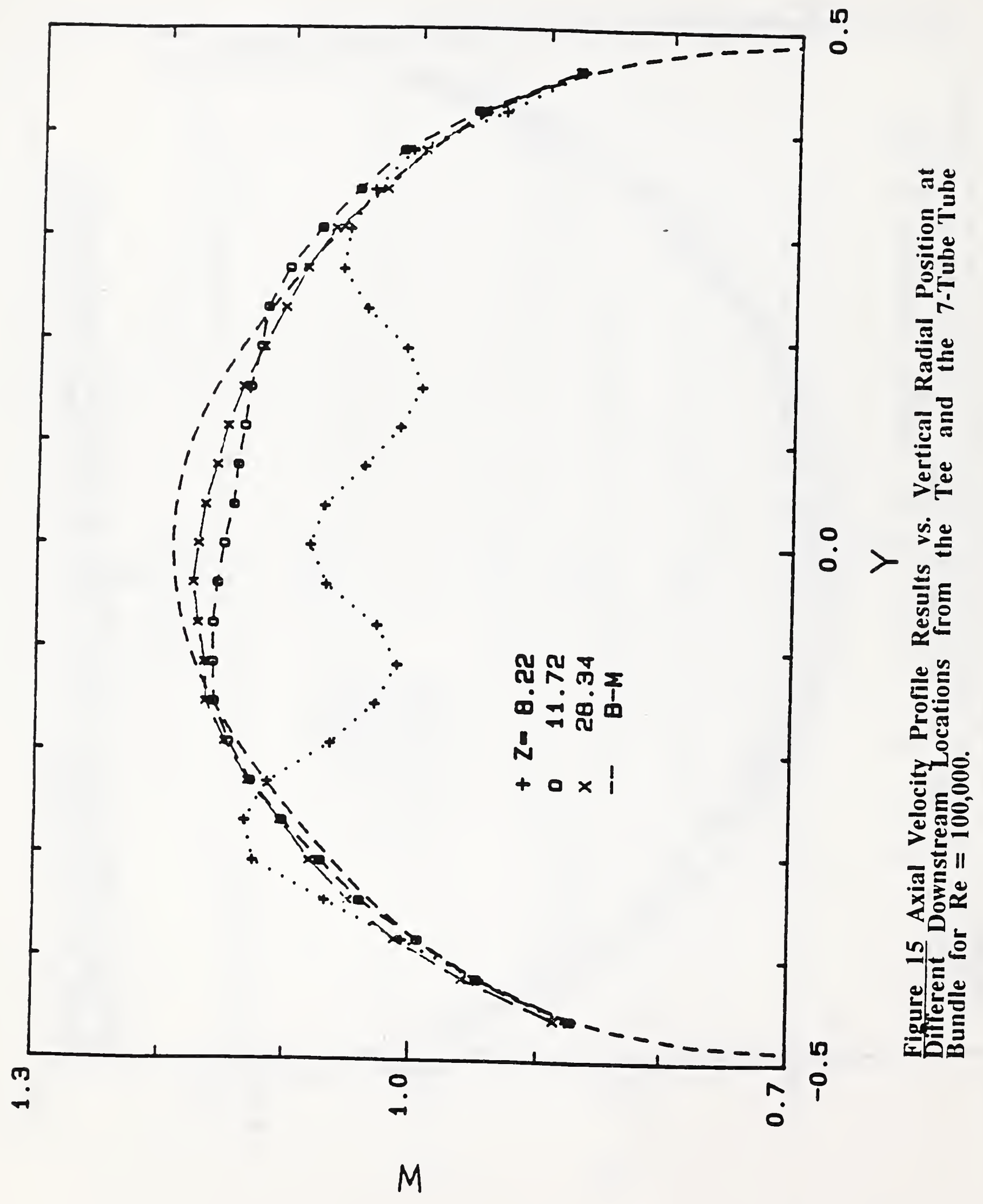




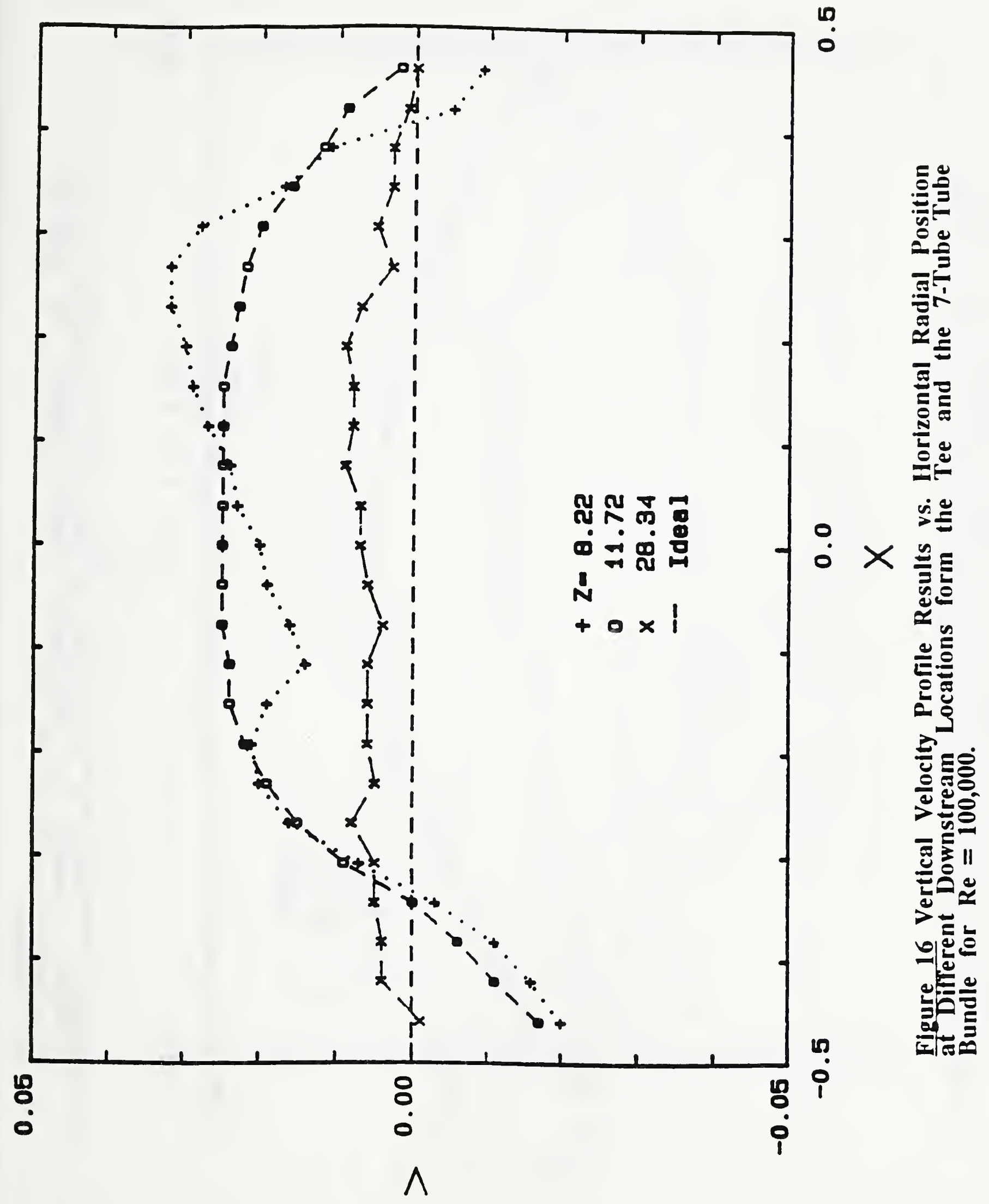




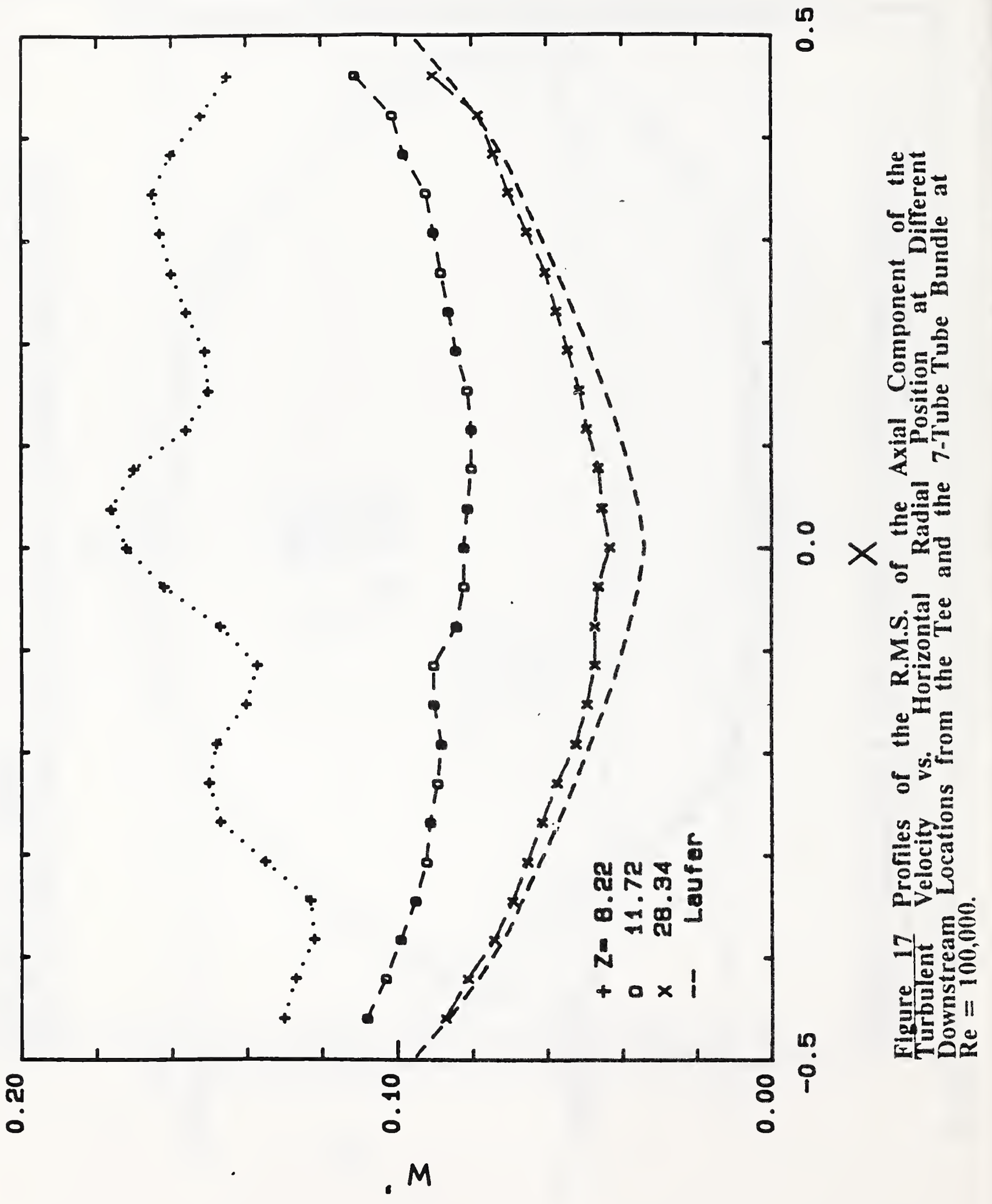




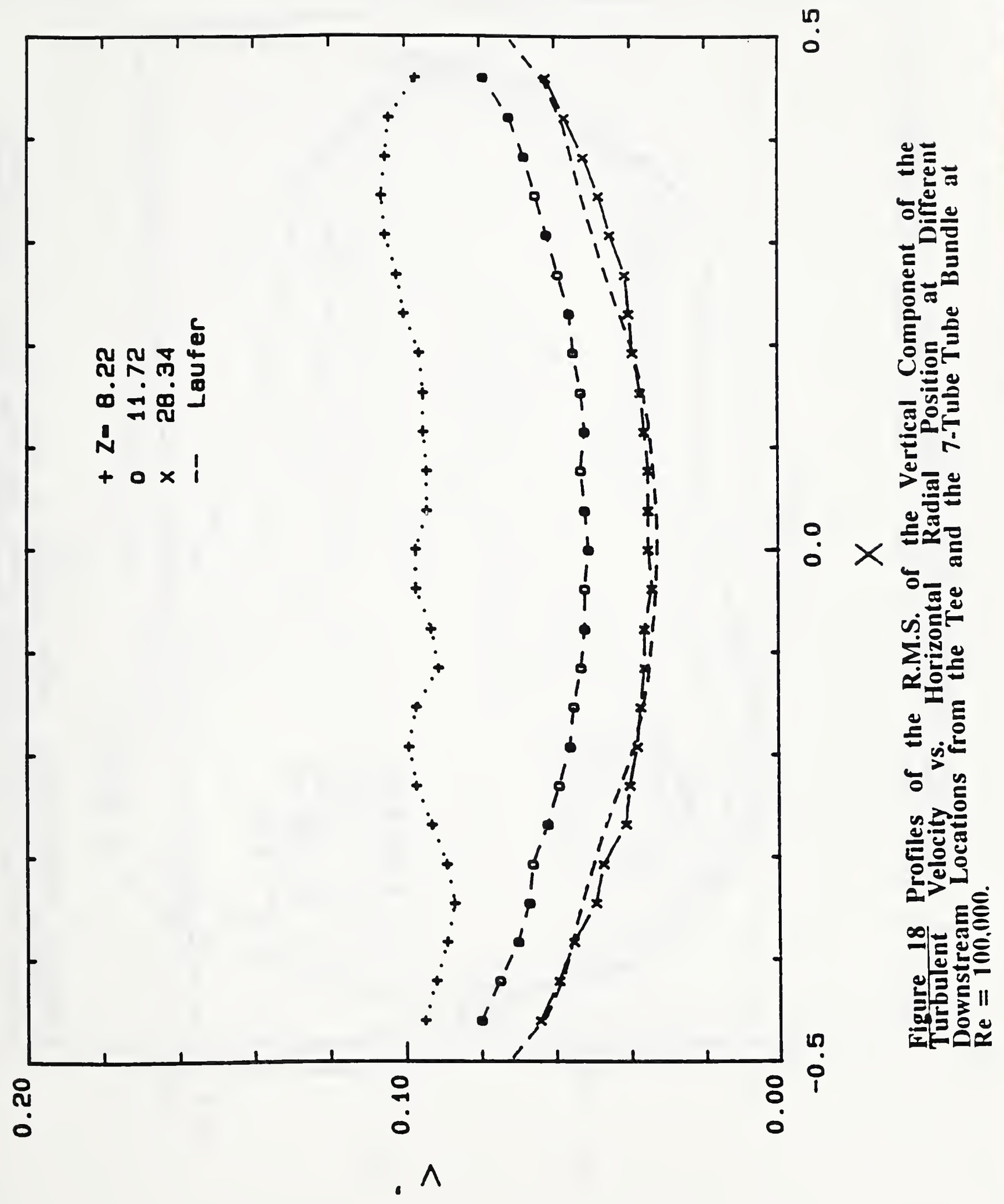




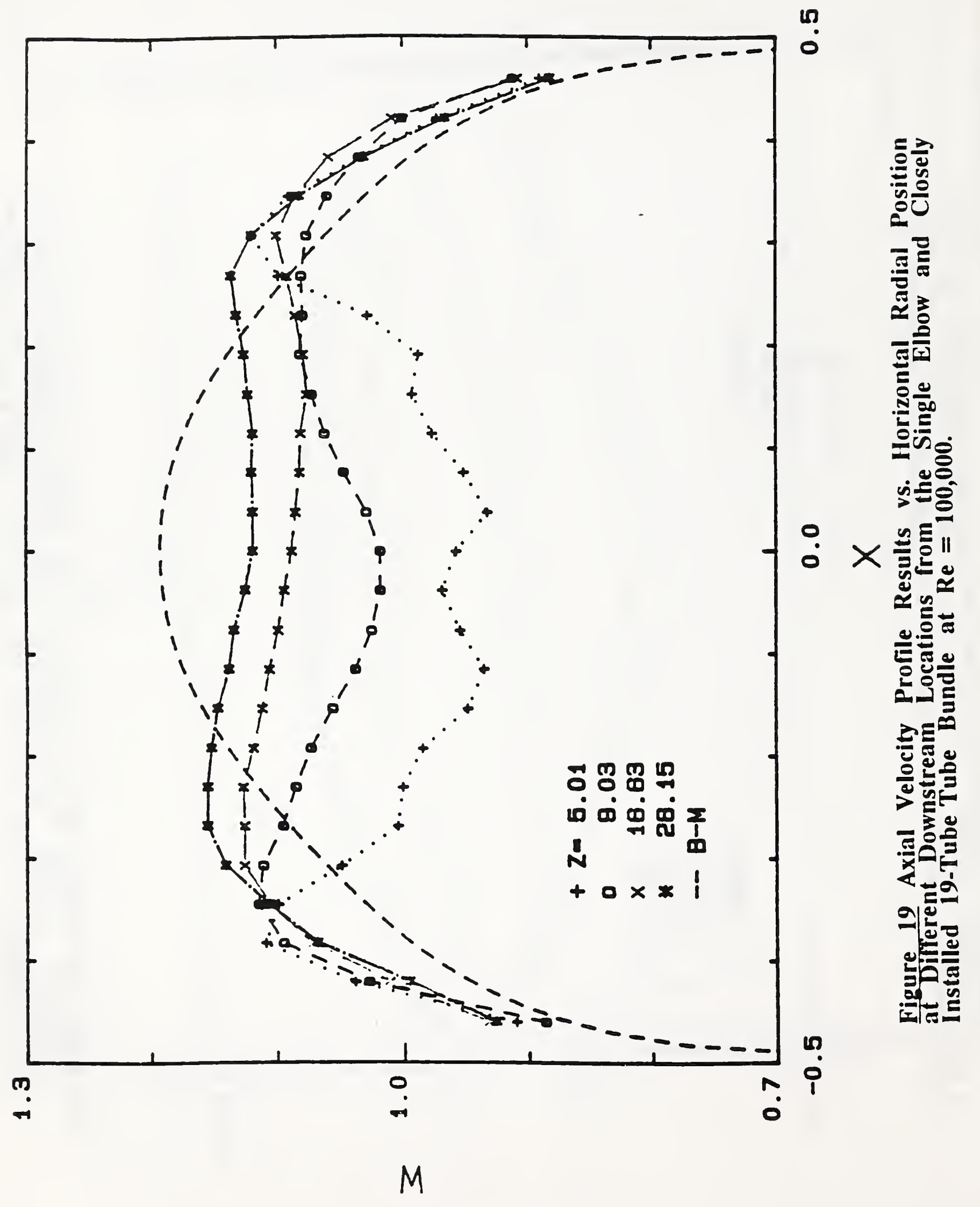




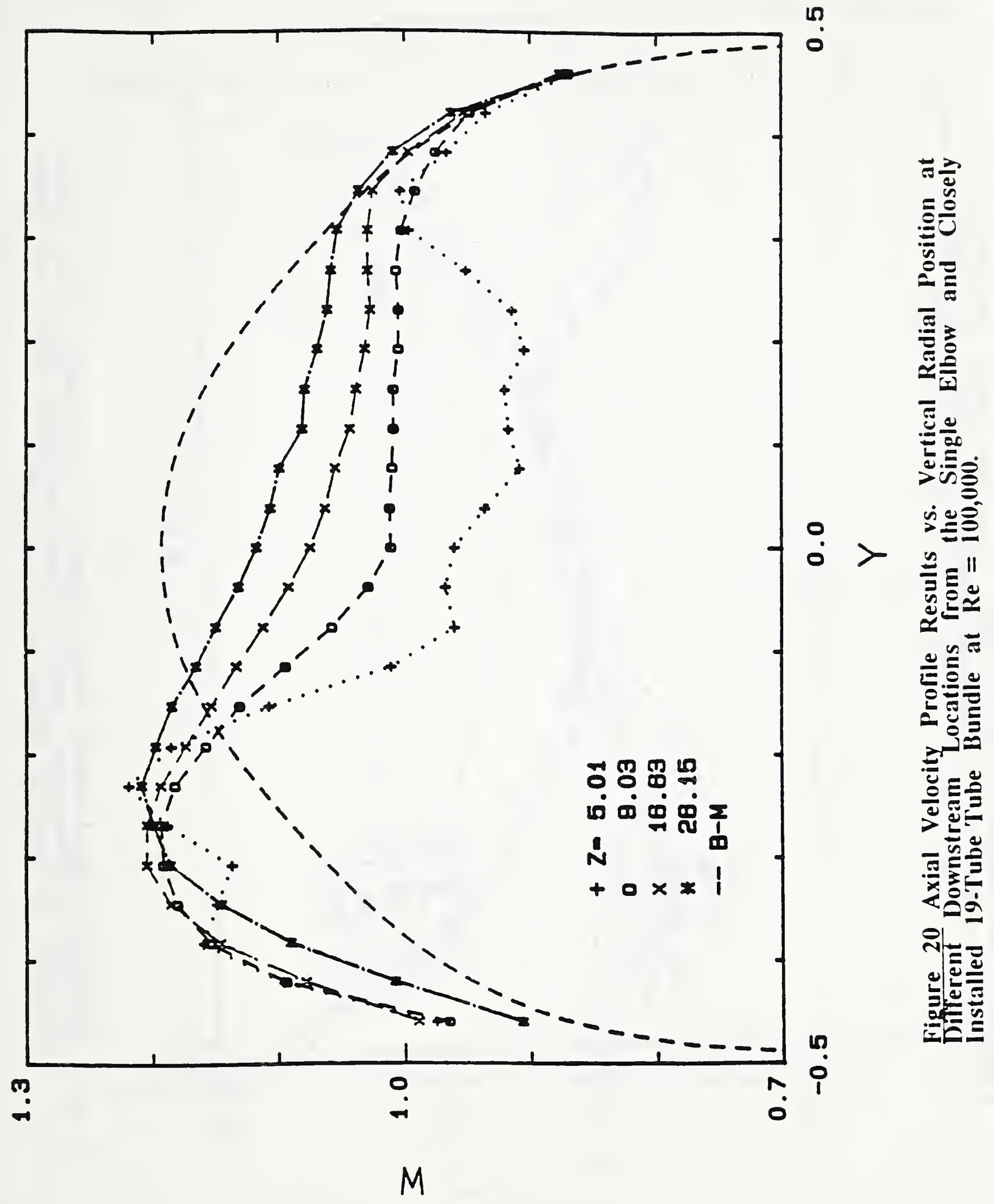




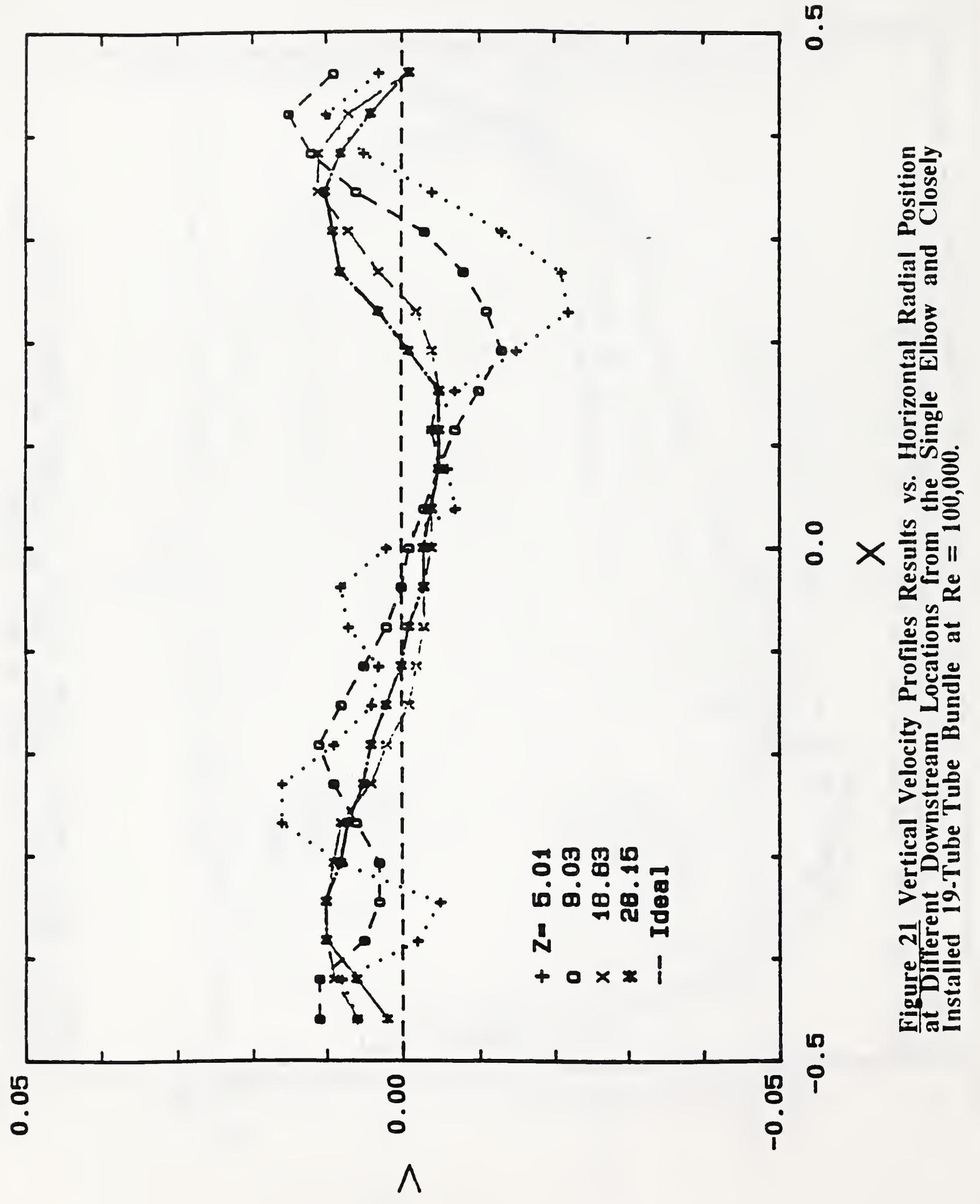




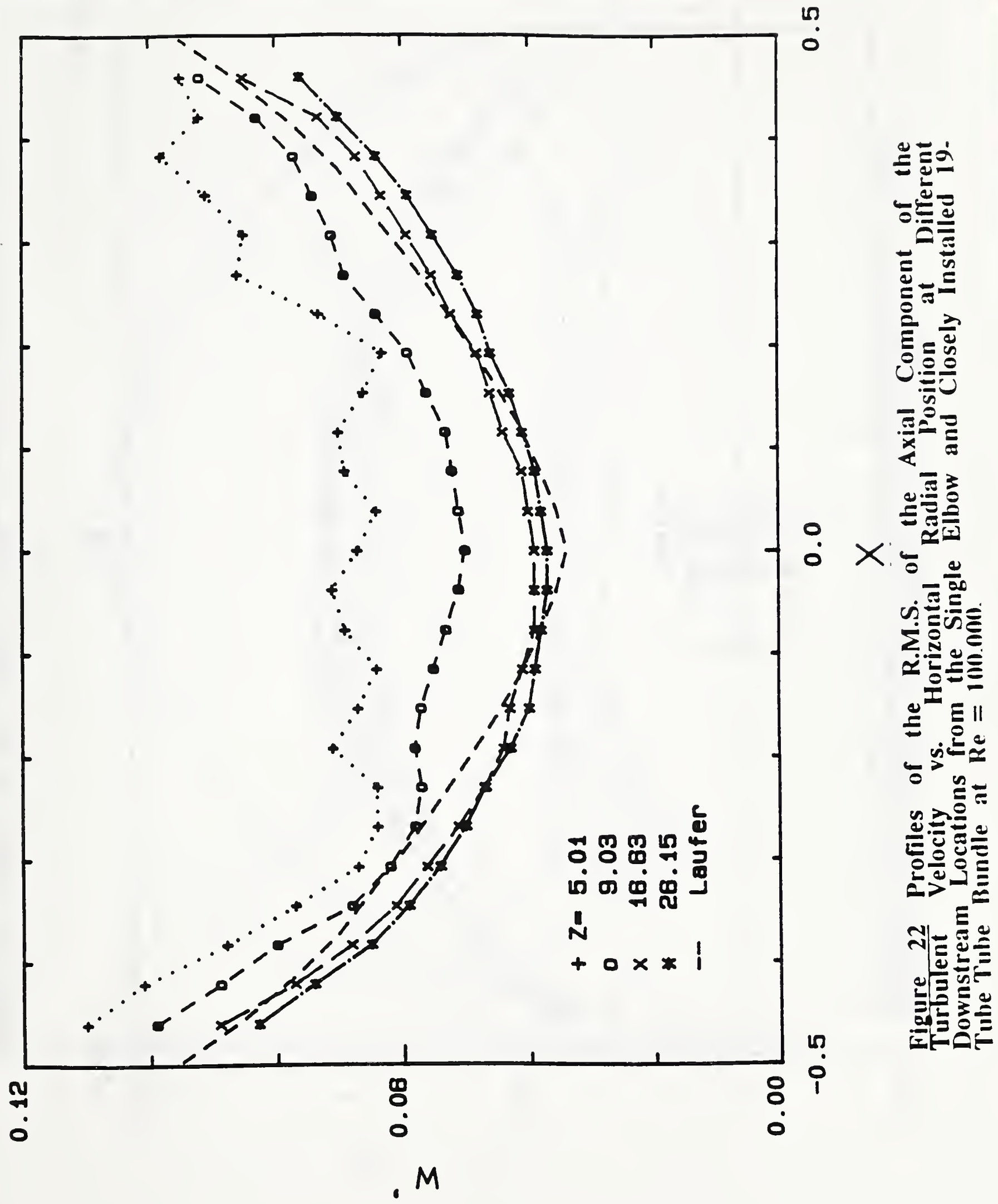




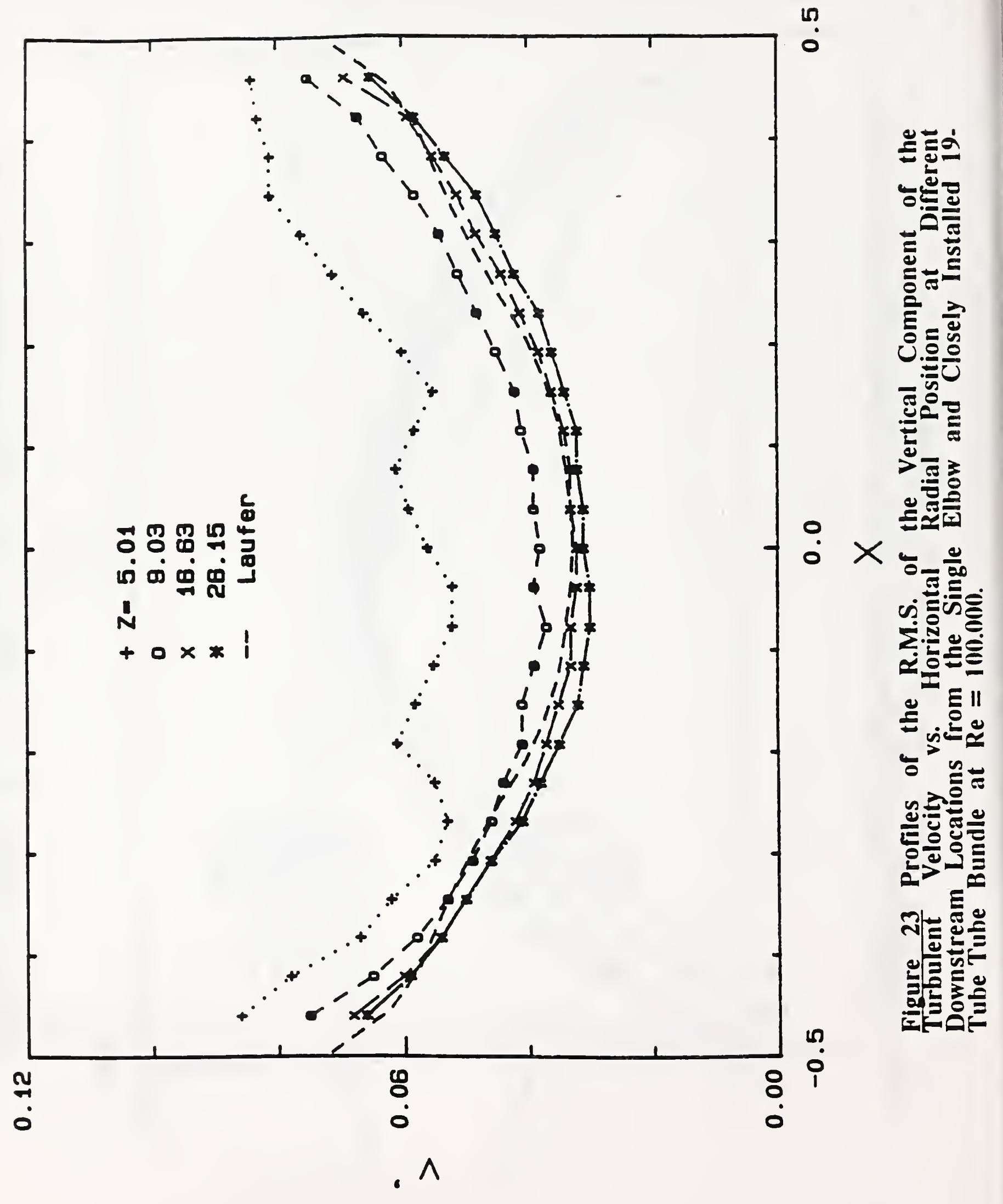




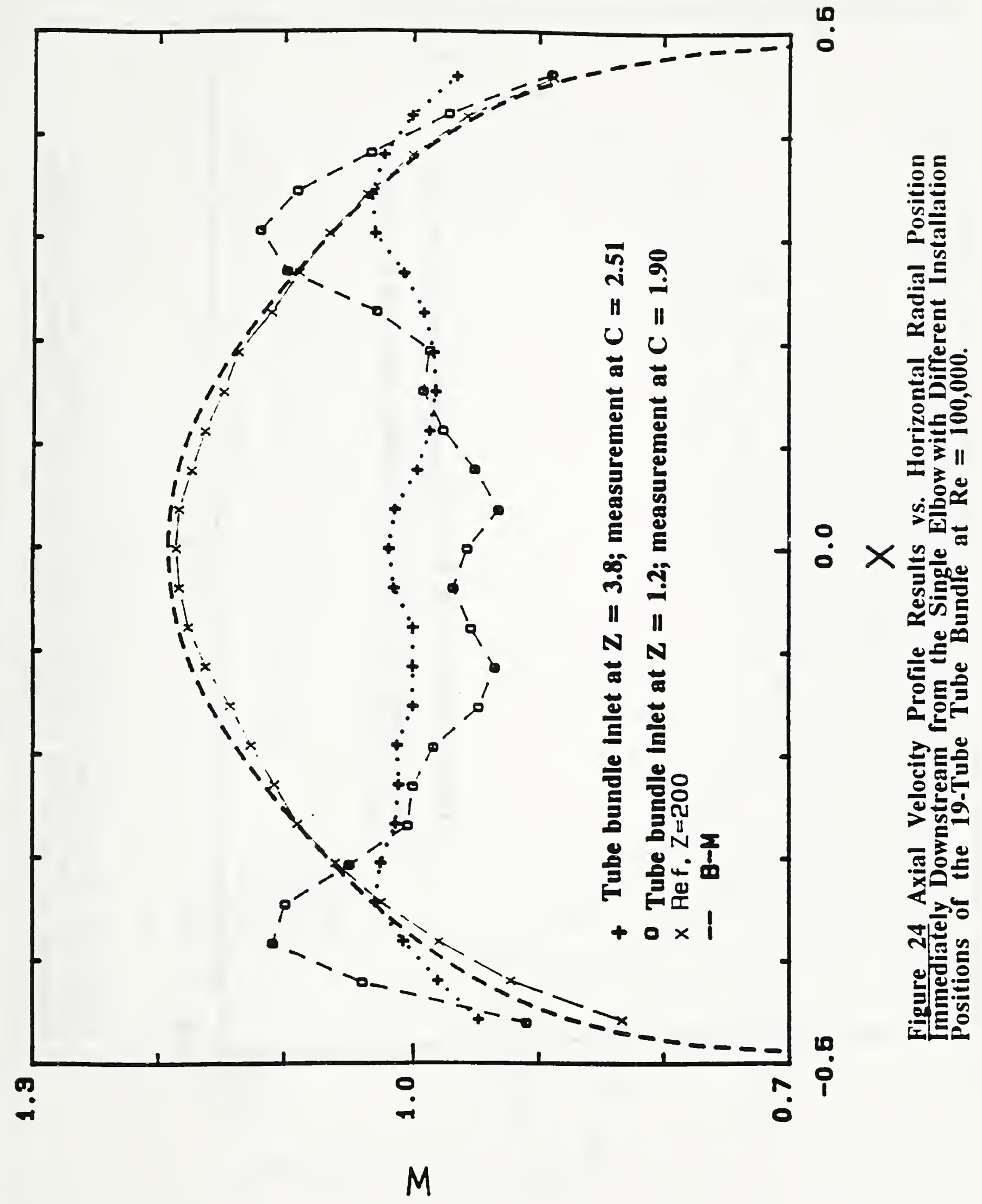




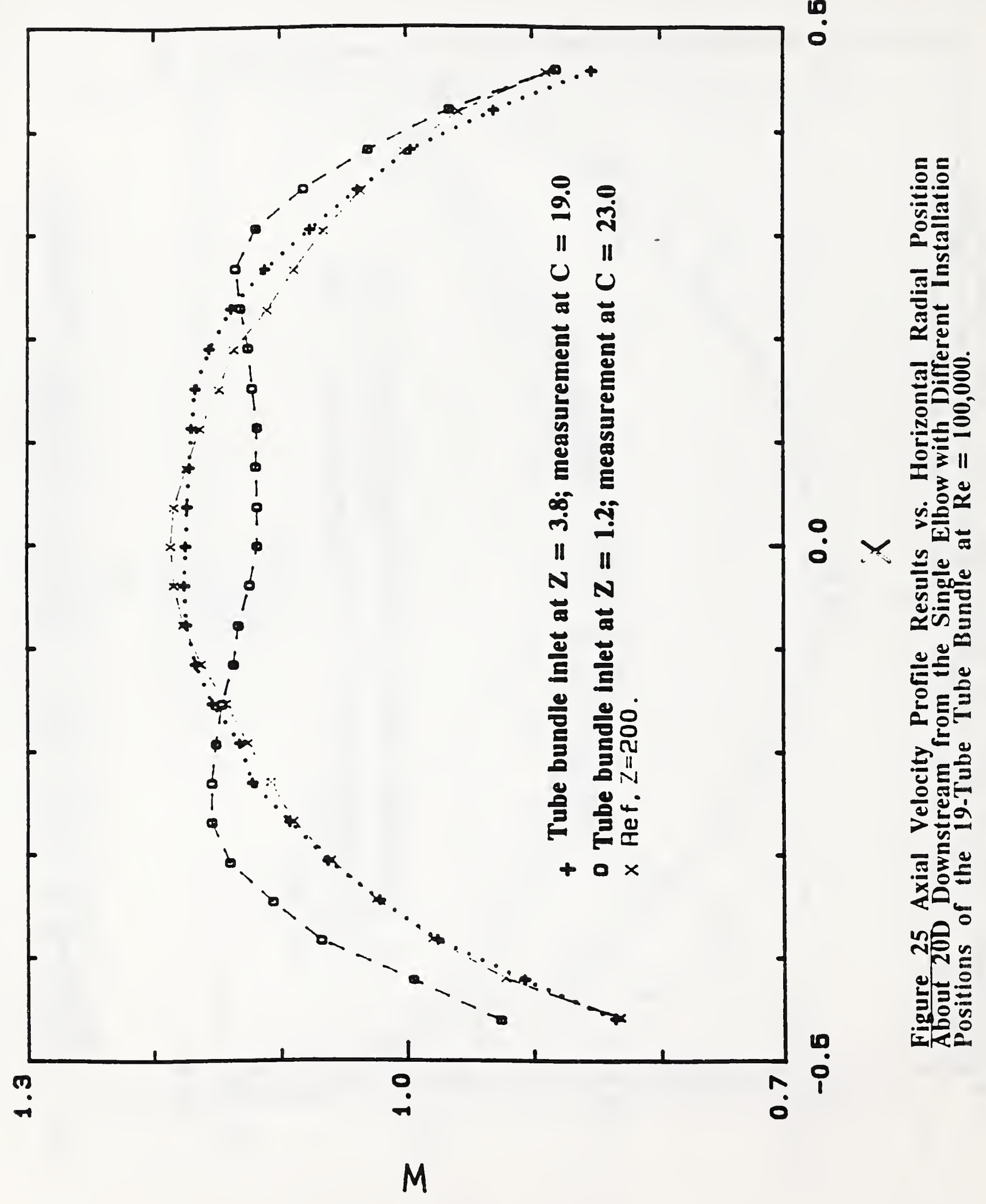




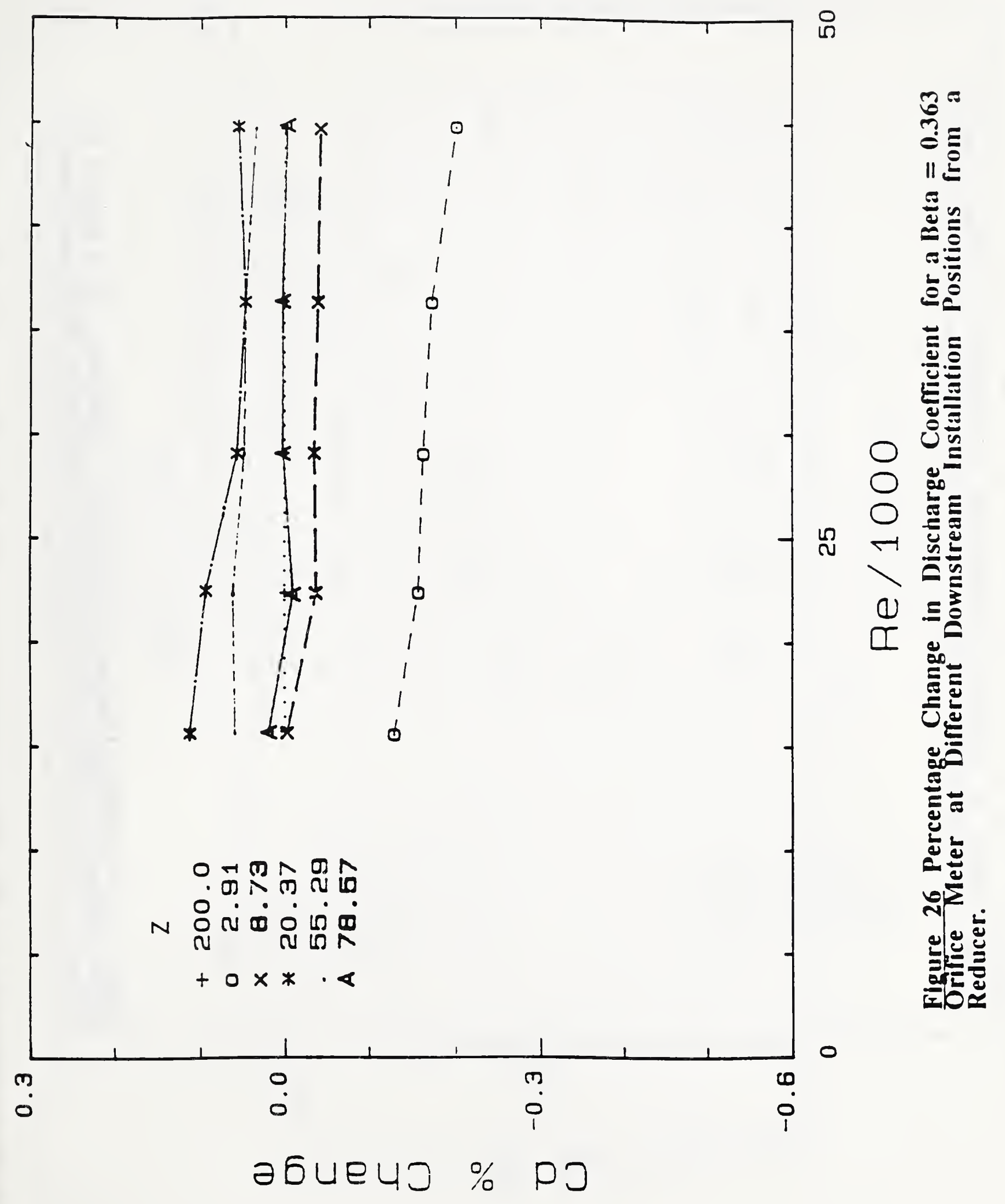




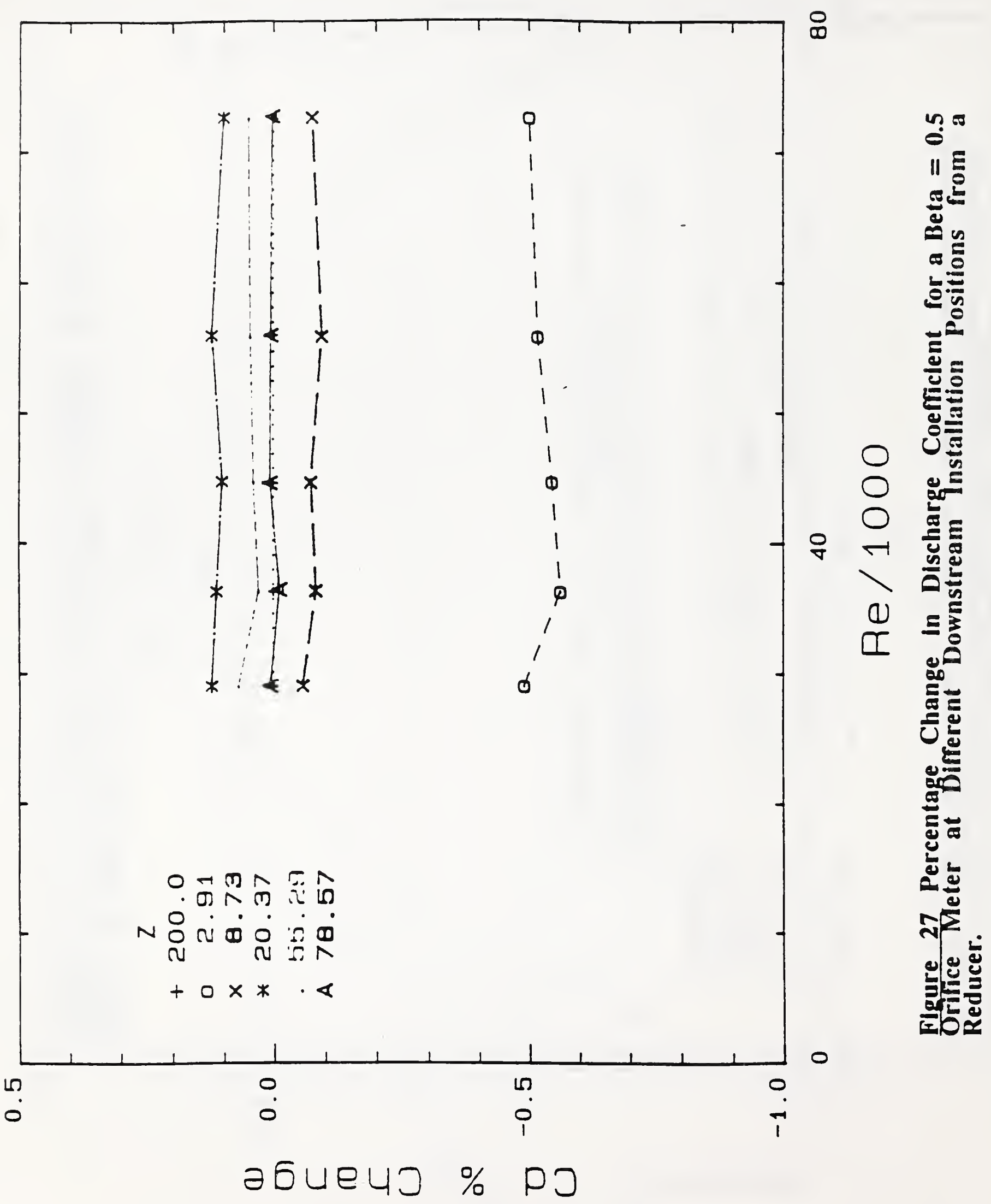




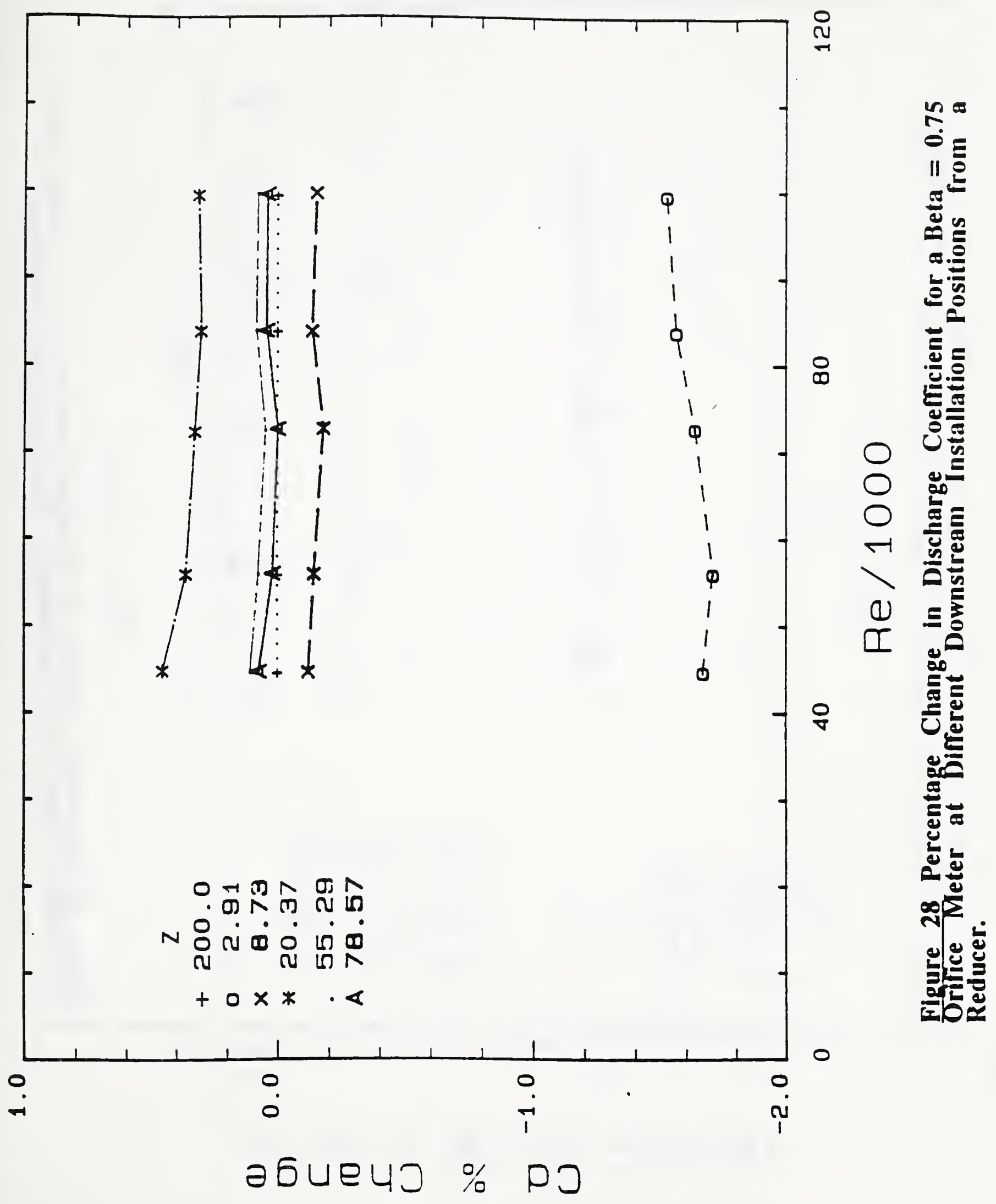




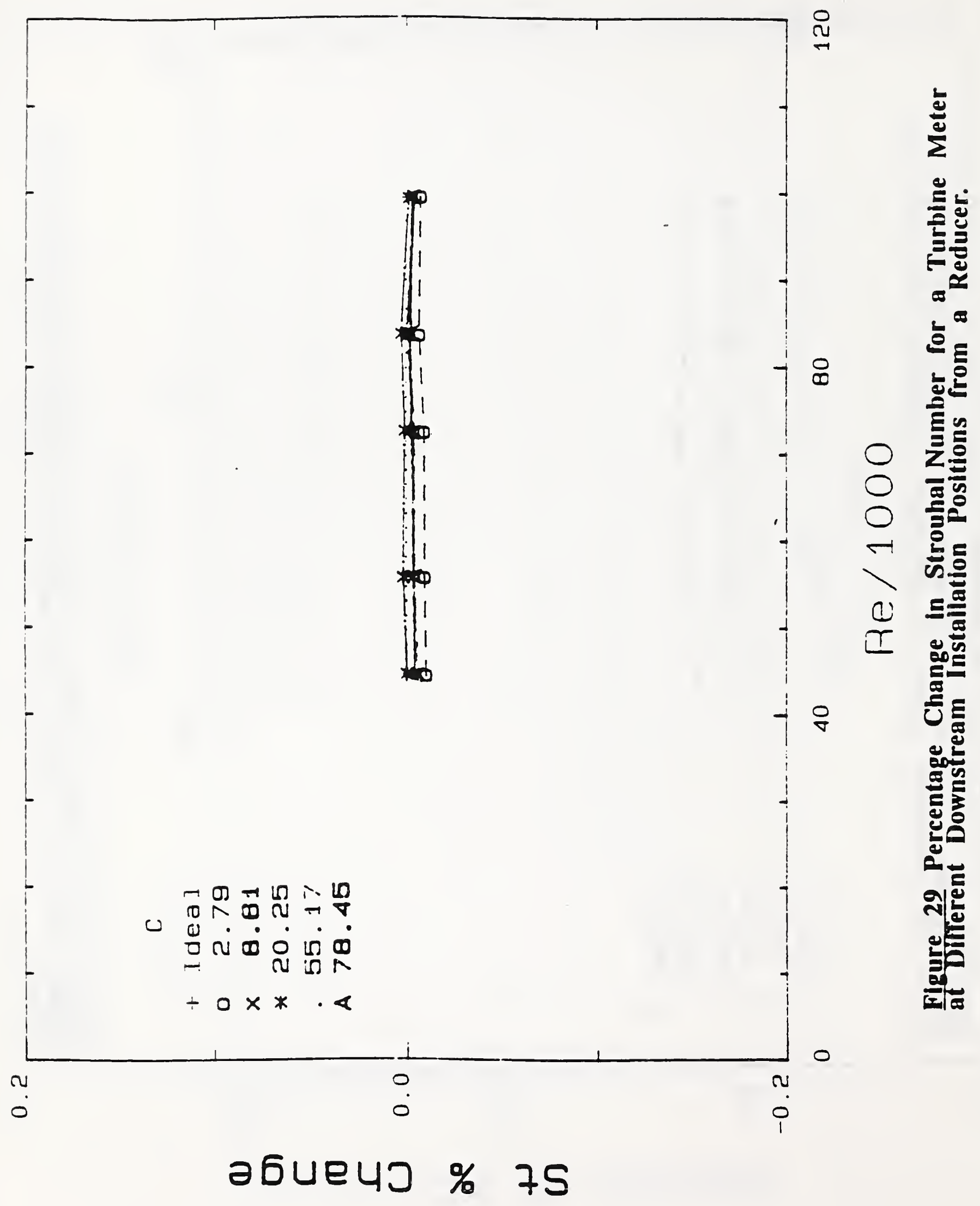




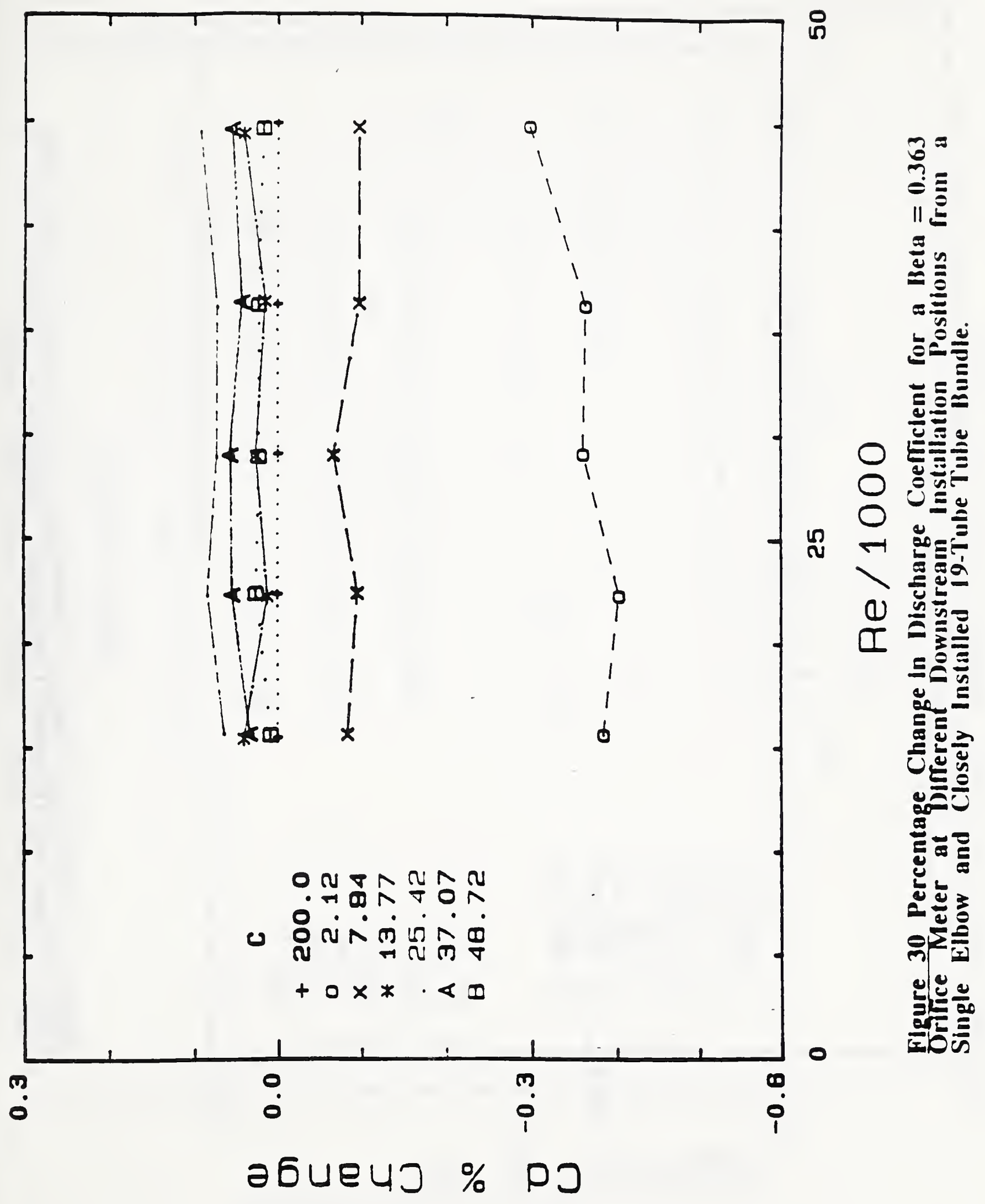




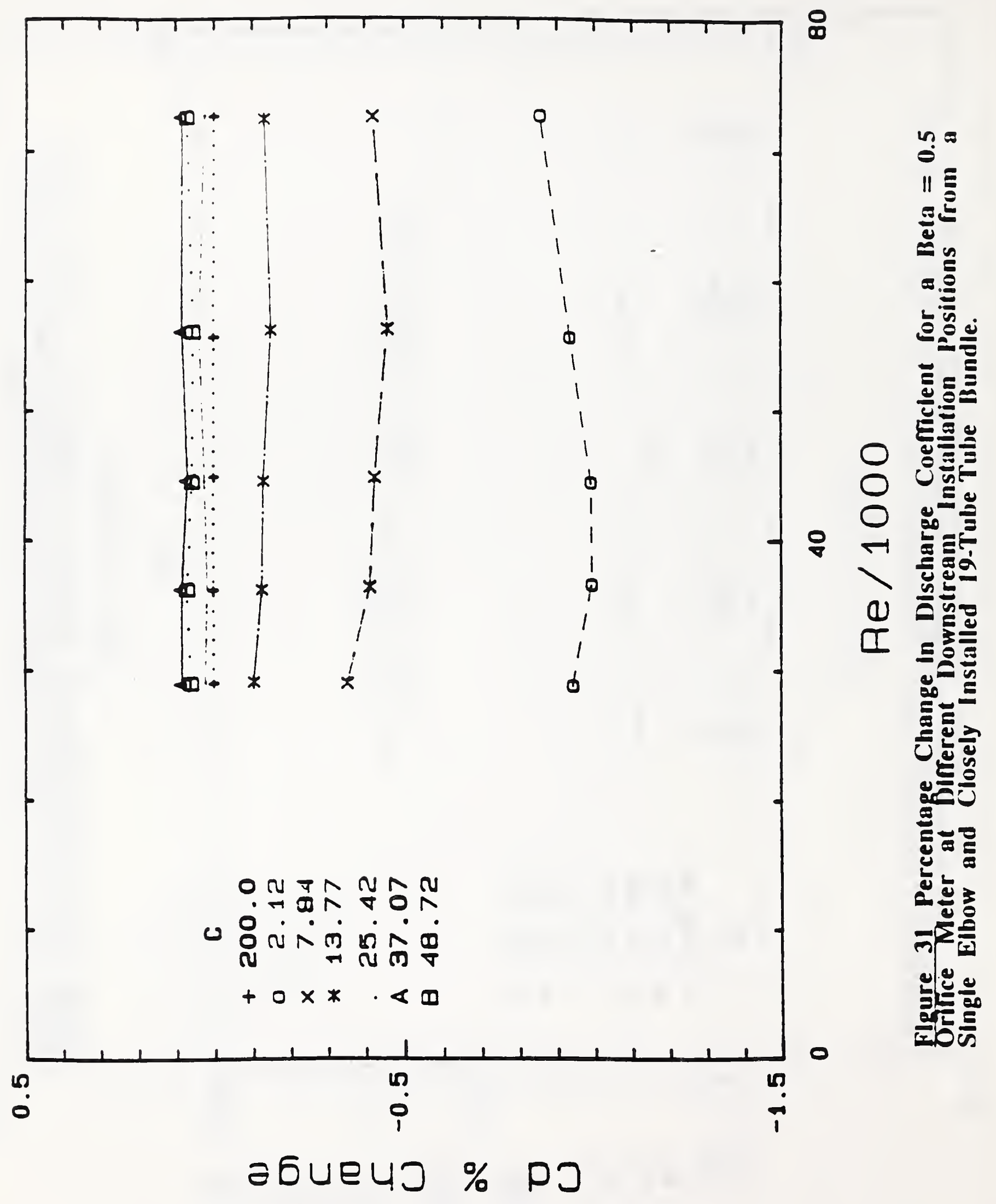




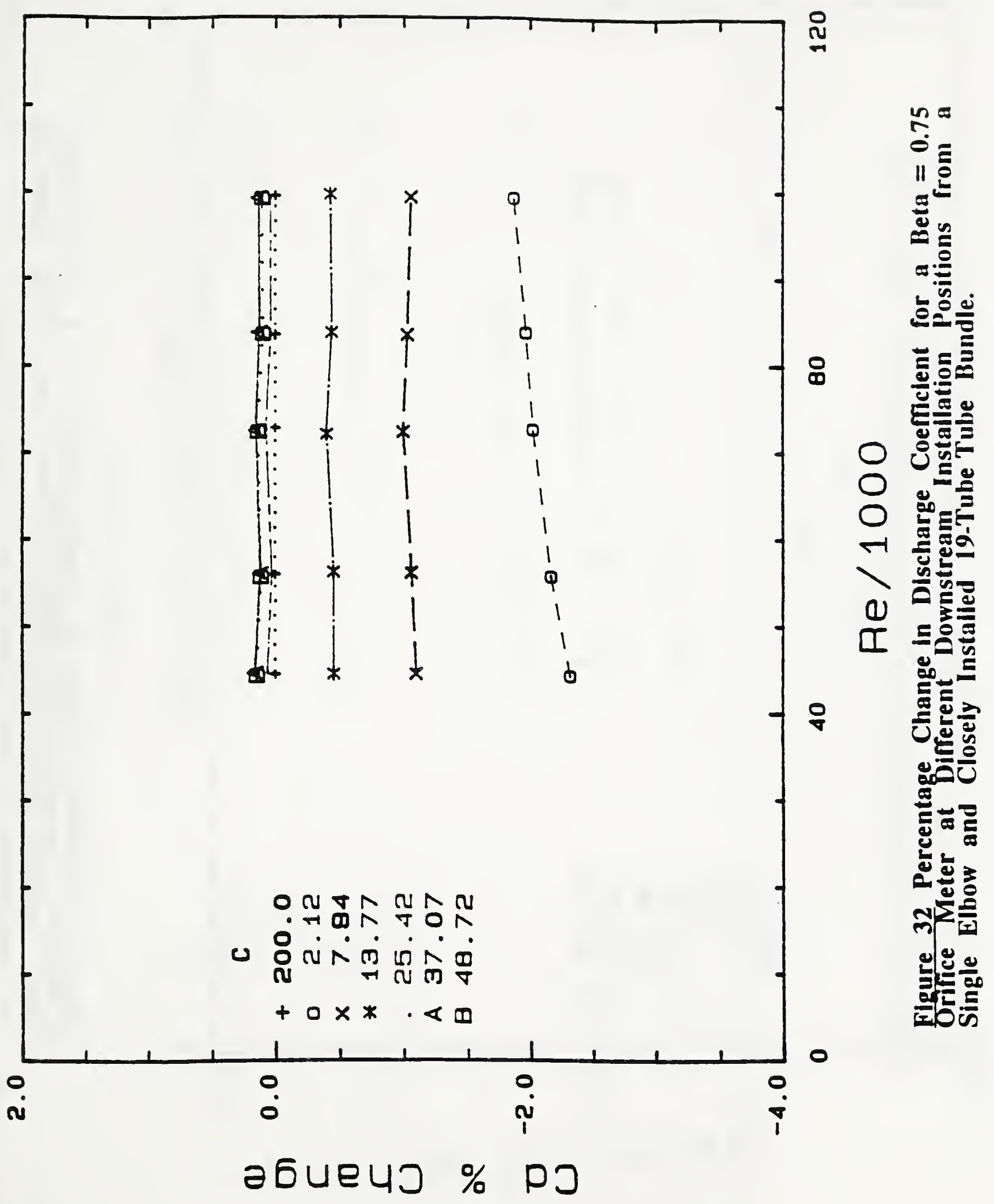




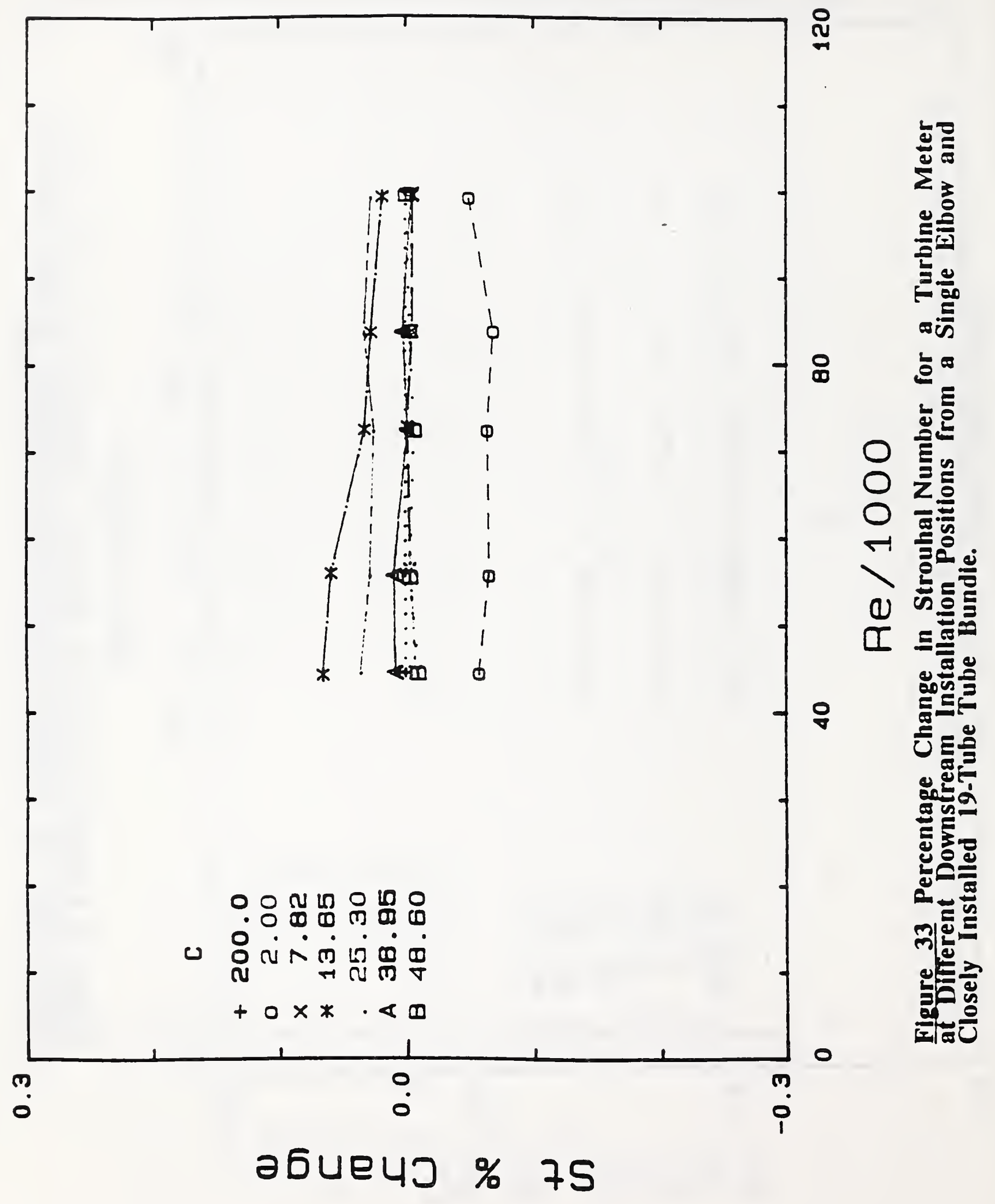




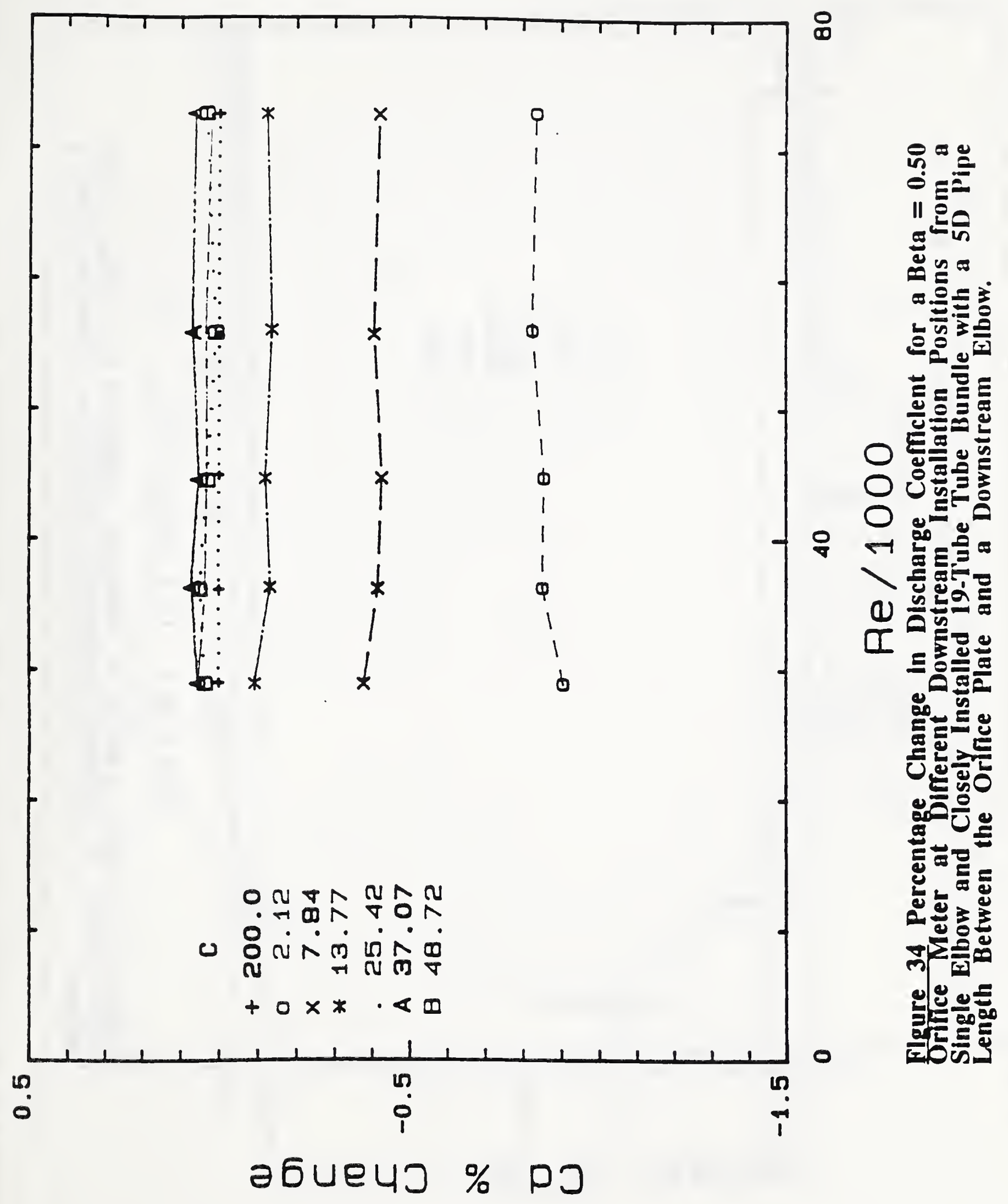




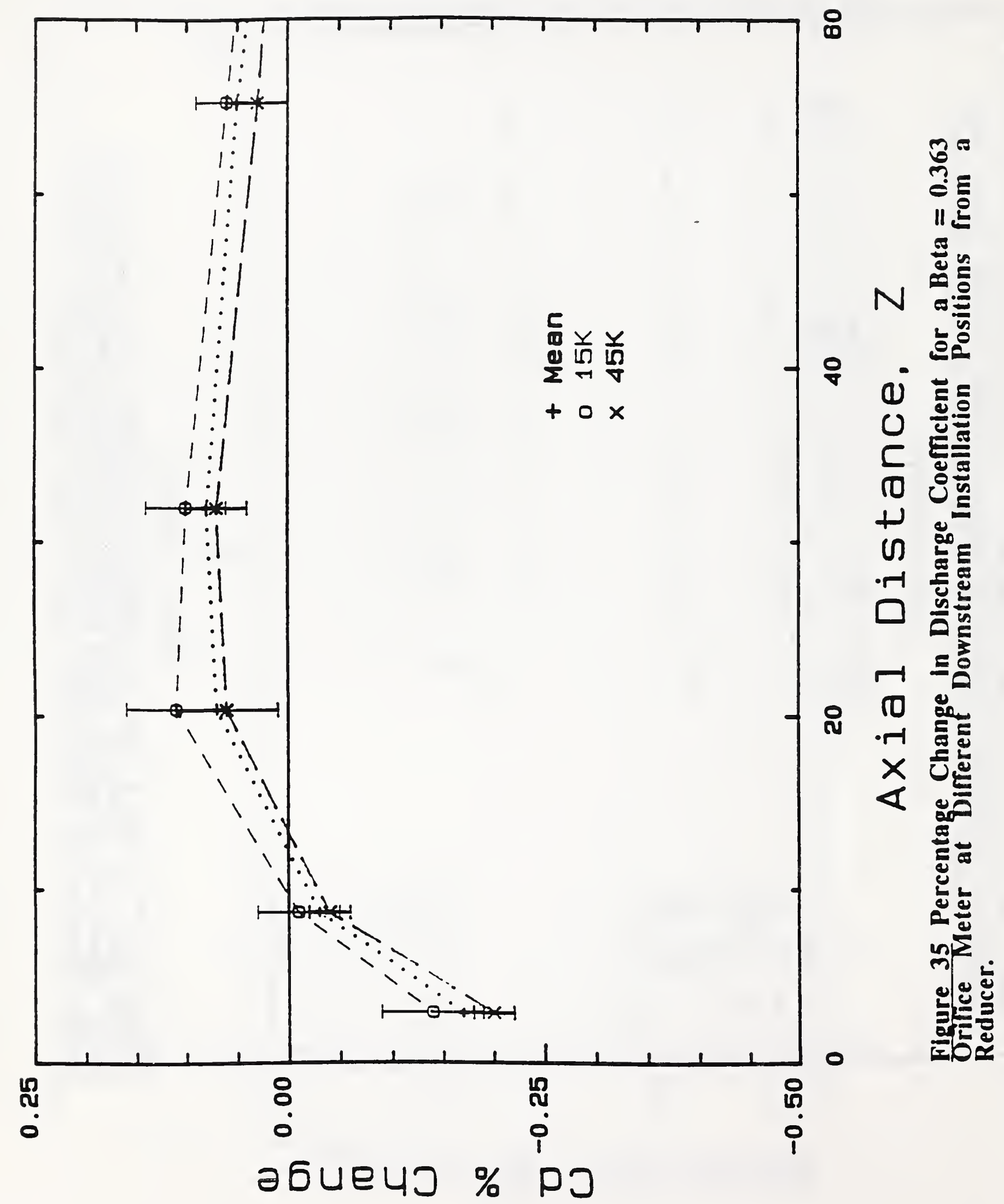




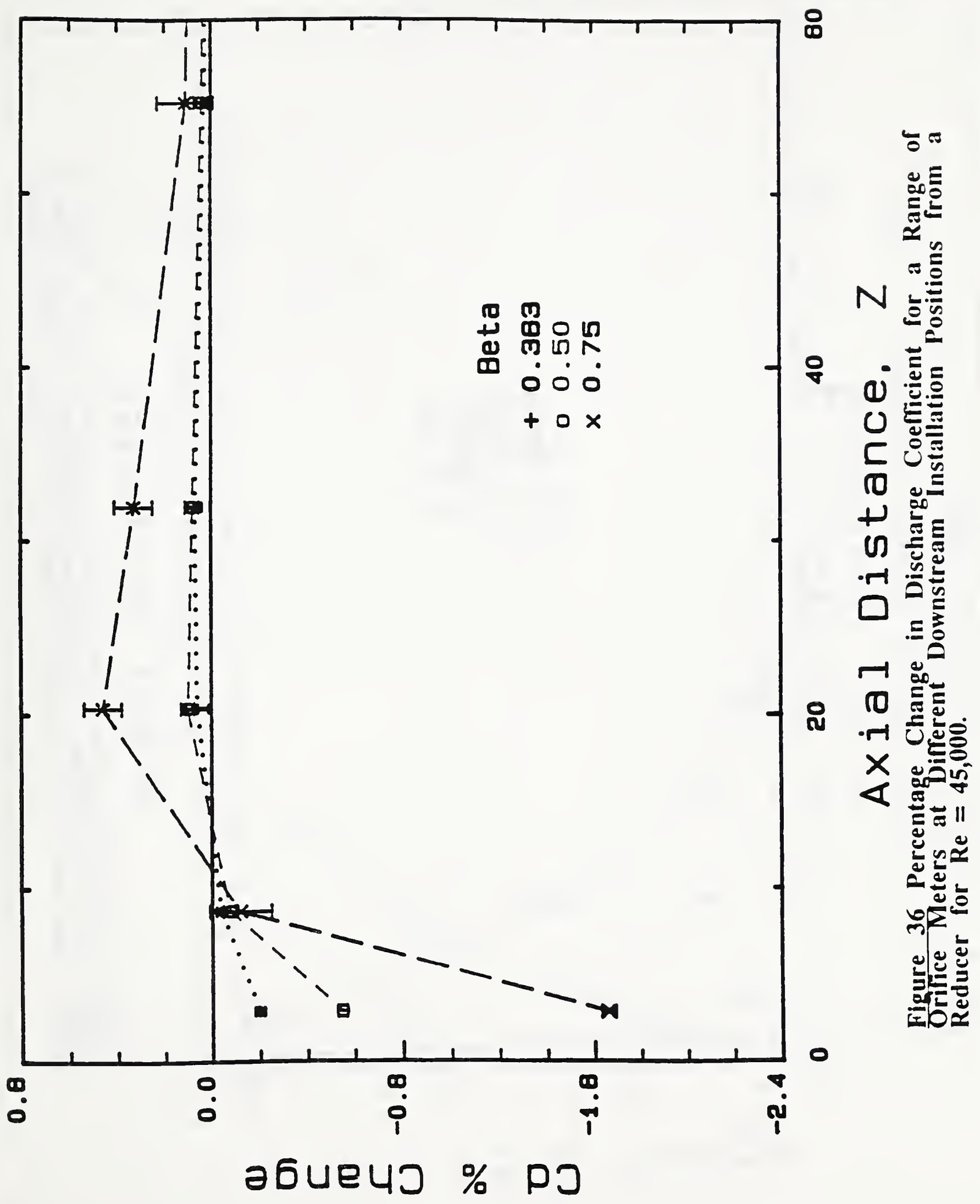




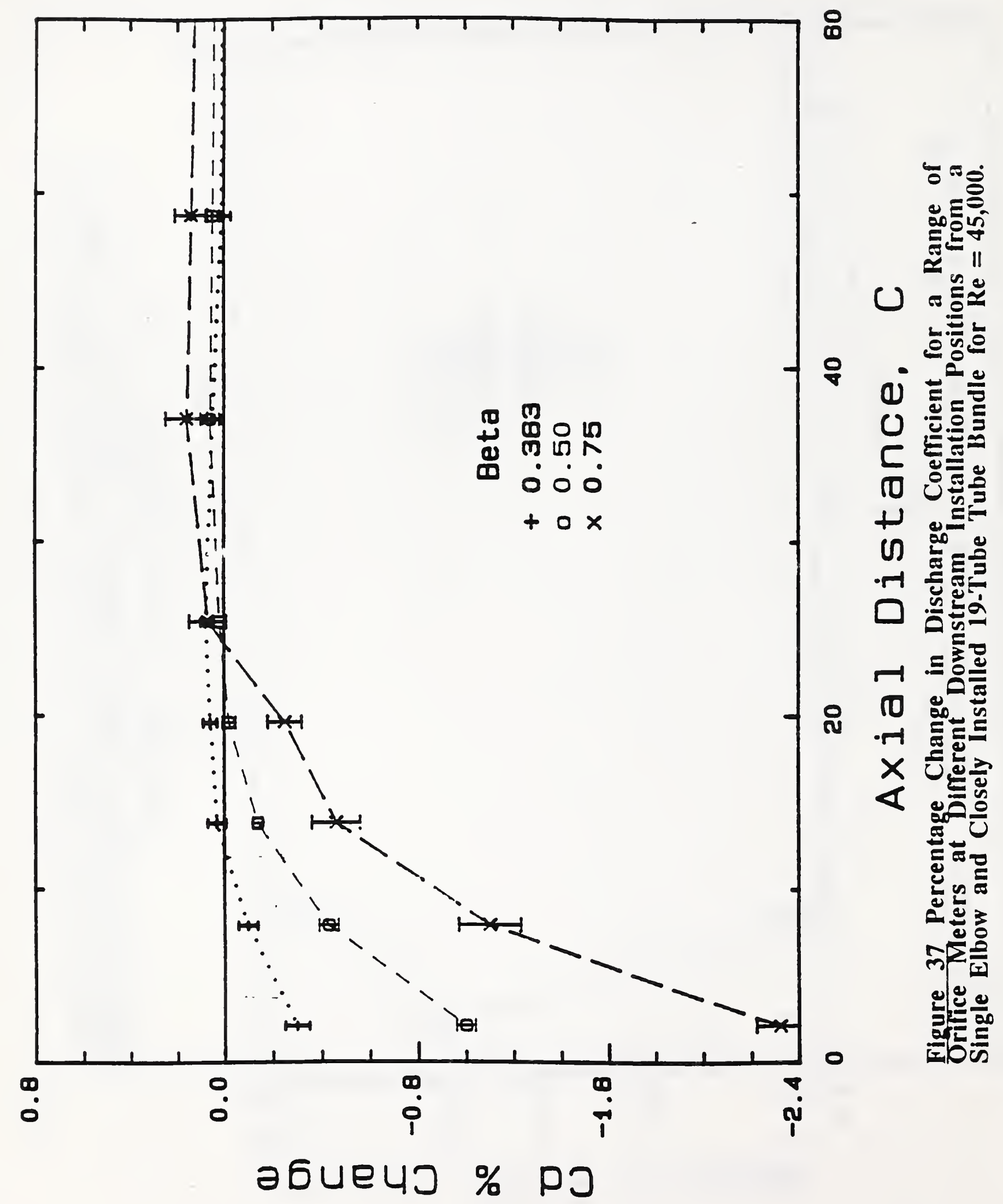




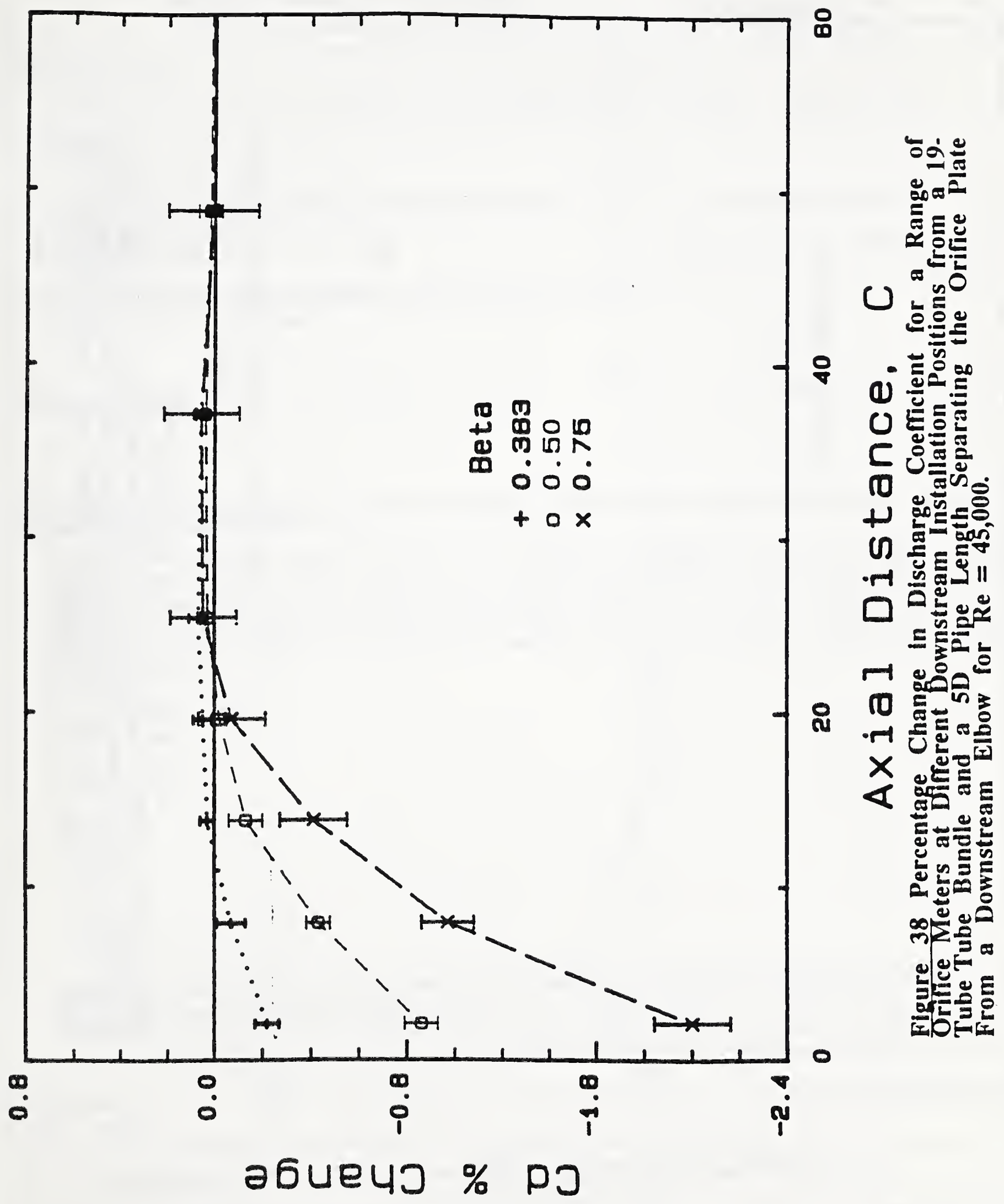




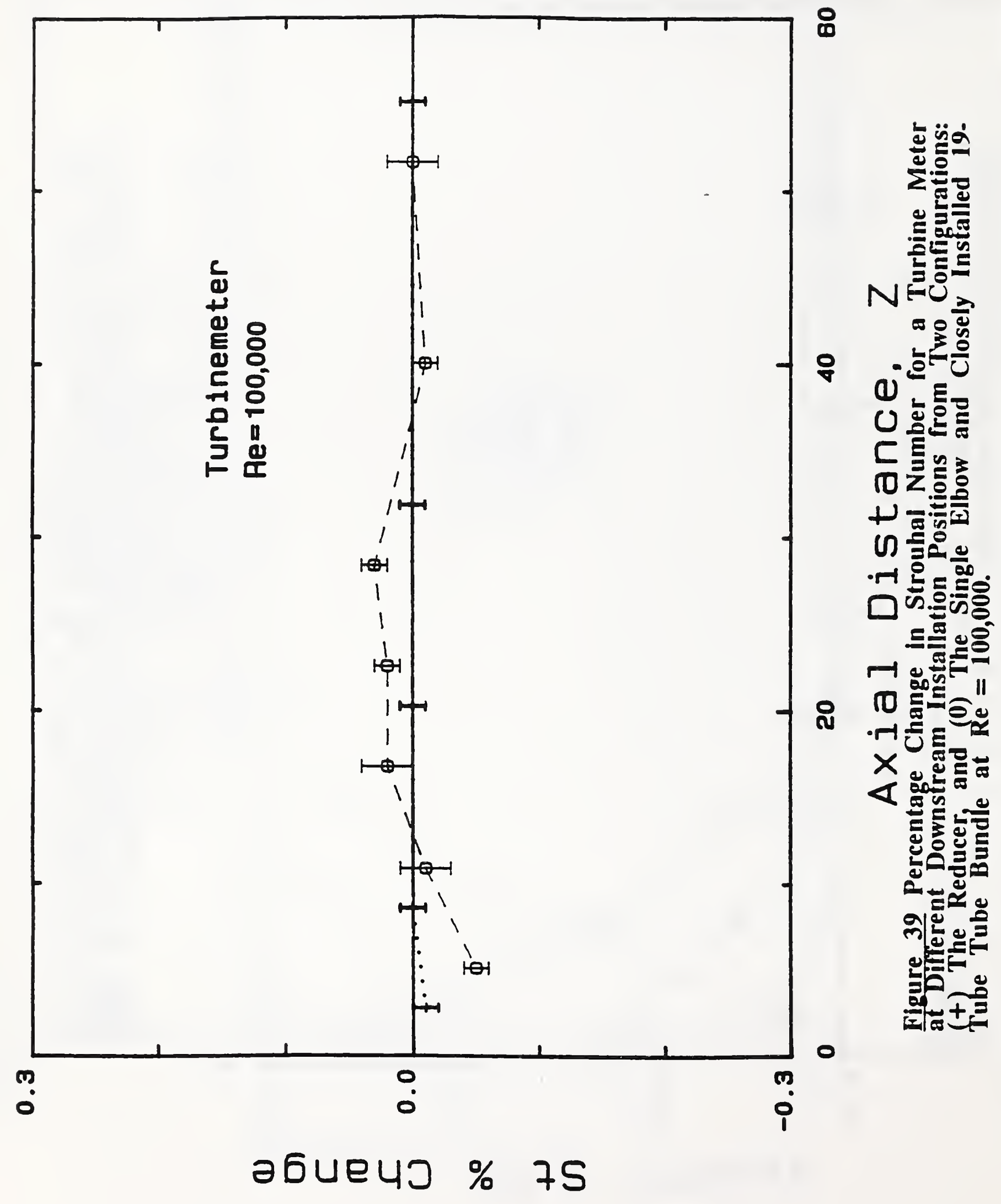




\begin{tabular}{|c|c|c|}
\hline $\begin{array}{l}\text { NIST-1144 } \\
\text { (REV. 3-80) }\end{array}$ & $\begin{array}{l}\text { U.S. DEPARTMENT OF COMMERCE } \\
\text { NATIONAL INSTITUTE OF STANDARDS AND TECHNOLOGY }\end{array}$ & $\begin{array}{l}\text { 1. MUUCATIOM OA AEPOAT MUMEEA } \\
\text { NISTIR } 4779\end{array}$ \\
\hline & & PEAFORMINO ORQWIZATION АEPOAT MUMLER \\
\hline & BIBLIOGRAPHIC DATA SHEET & 2. MUEUCATHOH DATE \\
\hline & & EEBRUARY 1992 \\
\hline
\end{tabular}

4. TITES AND SUSTITLE

Summary Report of NIST's Industry-Govermment Consortium Research Program on Flowmeter

Installation Effects with Emphasis on the Research Period January - September 1991: The Reducer

5. AUTHOA(S)
G. E. Mattingly and T. T. Yeh

6. PERFORMINQ ORQANDATION (IF JOINT OR OTHER THAN MIST, SEE INSTRUCTIOMS)

U.S. DEPARTMETT OF COMMERCE

MATIONAL INSTITUTE OF STANDARDS AND TECHMOLOQY

cartienseuna, WD 20000

7. CONTMACT/ORANT MUMBER

6. TYPE OF REPORT AKD PEAIOD COVERED

9. SPONSOAIMO ORCAMLATIOH MAME AND COMPLTE NODAESS (STRERT, CTT, STATE, ZA)

NIST Industry Consortium

10. SUPAEDENTAY NOTES

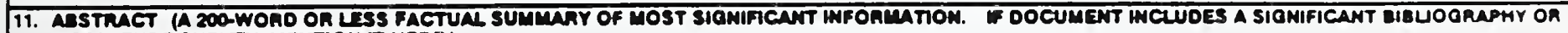
UTERATUAC sUAVT, MENTON $\pi$ MEShe)

This report presents results produced in a consortium-sponsored research program on flowmete installation effects. This project is a collaborative one that has been underway for eight years; it is supported by an industry-goverment consortium that meets twice yearly to review and discuss results and to plan subsequent phases of the work. This report contains the results and conclusions of the recent meeting of this consortium at NIST-Gaithersburg, YD in October 1991.

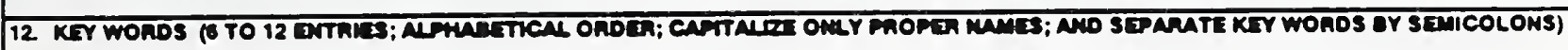

disturbed velocity profiles; double elbows; flow conditioning; non-ideal flowmeter perfomande reducer single elbow; swirl angle; swirl decay; swirled pipeflow; tee; tube bundle

13. AVAHNHTr

unumino

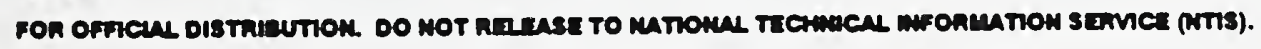

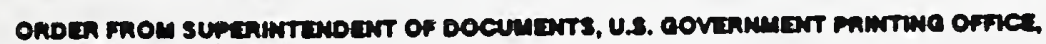
WASHunctom, DC zace.

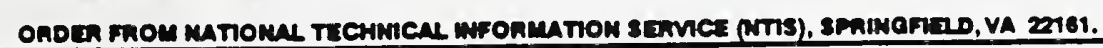

14. MUMLAT OF PNINTED PAOES -

\section{7}

15. mice

A.04 


